\title{
Effect of shear rate and pressure on the crystallization of PP nanocomposites and PP/PET polymer blend nanocomposites
}

Leire Sangroniz ${ }^{1}$, Martin van Drongelen ${ }^{2}$ Ruth Cardinaels ${ }^{3}$, Antxon Santamaria ${ }^{1}$, Gerrit W.M. Peters ${ }^{3 *}$, Alejandro J. Müller ${ }^{1,4 *}$

\begin{abstract}
${ }^{1}$ POLYMAT and Polymer Science and Technology Department, Faculty of Chemistry, University of the Basque Country UPV/EHU, Paseo Manuel de Lardizabal 3, 20018, Donostia-San Sebastián, Spain
\end{abstract}

${ }^{2}$ Faculty of Engineering Technology, Chair of Production Technology, University of Twente, Drienerlolaan 5, 7255 NB, Enschede, The Netherlands

${ }^{3}$ Polymer Technology, Department of Mechanical Engineering, Eindhoven University of Technology, P.B. 513, 5600 MB Eindhoven, The Netherlands.

${ }^{4}$ IKERBASQUE, Basque Foundation for Science, Bilbao, Spain.

*Corresponding authors: A.J. Müller (alejandrojesus.muller@ehu.es) and G.W.M. Peters (G.W.M.Peters@tue.nl) 


\begin{abstract}
The effect of shear flow on the crystallization of homopolymers has been widely studied, however more complex systems such as nanocomposites or polymer blends nanocomposites (PBNANOs) has received less attention. In this work, the effect of pressure and shear flow on the crystallization process of polypropylene-based nanocomposites and polypropylene/polyethylene terephthalate PBNANOs has been studied employing dilatometry (PVT), X-ray, rheology, and DSC. The material systems used allow studying the effect of shear in the presence of nanoparticles that do not have a nucleating effect, as well as the combined effect of shear and nucleating nanoparticles. Nucleating nanoparticles increase the crystallization temperature more significantly because of the combined effect of nucleation and flow. For carbon nanotubes, nucleation is more pronounced due to stronger interactions with PP chains, as demonstrated by rheological measurements. For PBNANOs the effect of shear on crystallization is slightly more significant due to the higher amount of available surfaces.
\end{abstract}

Keywords: Nanocomposites, Polymer blend nanocomposites, Crystallization, Pressure, Shear flow 


\section{INTRODUCTION}

Nowadays, polymers are used in a very wide range of applications, such as packaging, automotive industry, medicine, civil engineering, and others. Within this framework, the urgency to develop innovative materials with improved performances that fulfill the requirements from the point of view of application as well as processing has lead to the development of polymer nanocomposites, i.e., polymer matrices filled with particles of dimensions at the nanoscale. Their main advantage is that the addition of small quantities of nanoparticles (between 1 and 5\%) results in significant improvements of the mechanical, thermal and, in case of conductive nanoparticles, electrical properties. Moreover, sometimes, more complex systems are needed to meet the challenging requirements of some applications; therefore polymer blends containing nanoparticles, also known as PBNANO's, have been developed [1-9]. Polymer blends have the advantage that they combine the properties of multiple materials, thereby allowing, for instance, to tailor the mechanical performance as well as the transport properties of vapor and gases. Adding nanoparticles not only allows to improve these properties further or introduce additional properties but can also be used to stabilize and refine the polymer blend morphology [5]. From a sustainability point of view, the development of PBNANO's could be useful to improve the properties of recycled materials or biobased materials, which show poor mechanical and barrier performance.

The performance of polymer nanocomposites, as well as PBNANOs, has been studied in detail [1-9], and the different parameters that affect the properties of the materials have been established, such as the dispersion level, the effect of particle size and aspect ratio, the location of the nanoparticles in a polymer blend and their effect on the blend morphology, etc. Several reviews have already reported on the effect of these parameters on rheological, thermal and mechanical properties, and in the case of conductive nanofillers, such as carbon nanotubes (CNT), the conductivity has been thoroughly studied [1-9].

While the relationship between morphology and blend structure and final properties has been studied extensively, the effect of processing conditions on the final morphology and crystallinity has been treated far less. During processing polymer materials are submitted to high pressures, shear rates and cooling rates that can have a strong influence on the crystalline morphology and, in the case of polymorphic 
polymers, different crystalline phases are developed depending on the processing conditions [10-16].

In the literature the effect of flow on polymer crystallization has been thoroughly studied, demonstrating that flow can not only modify the crystallization kinetics due to its effect on the nucleation step but, it can also affect the crystalline morphology, generating for instance oriented structures like shish-kebabs instead of spherulites. In the case of polymorphic polymers, as for poly(propylene), different crystal phases can be generated depending on the flow conditions [17]. Depending on the crystalline morphology and crystalline phases, the final properties of the material change [18-21].

The effect of shear rate on crystallization has attracted a lot of interest; the work on the combined effect of pressure and shear rate is less abundant. Such studies are truly relevant since, in processing conditions, the materials are summited to high pressures and shear rates at the same time. In literature, the (combined) effect of pressure, shear rate, and cooling rate on crystallinity have mostly been studied for polyolefins. Van Erp et al. [14] and Van Drongelen et al. [13] studied the effect of shear rate and cooling rate on the crystallization of polypropylene (iPP) under different pressures. They found that depending on the shear rate, three different regions could be distinguished for iPP: at low shear rates there was no effect of flow, at intermediate shear rates more point nuclei were created thereby increasing the crystallization temperature, $T_{c}$, and at high shear rates the generated nuclei were oriented which resulted in oriented crystalline structures like shish kebabs. The authors studied the effect of the shear rate as well as the cooling rate on the formation of the different crystalline forms of PP. Regarding the effect of pressure, Van Drongelen et al. [13] found that increasing the pressure applied to the material the crystallization temperature was increased due to the increase of the equilibrium melting temperature, $T_{m}{ }^{0}$. They also observed that the increase of pressure provoked an increment of the gamma crystalline phase of PP, whereas alpha phase content was reduced; however at really high cooling rates $\left(90^{\circ} \mathrm{C} / \mathrm{s}\right)$ no gamma phase was formed.

The effect of shear rate and pressure was also studied in a multiphasic system constituted by an ethylene-propene copolymer, which was modified by adding ethylene-co-octene (EOC) or high-density polyethylene [16]. The final morphology of the samples obtained using different shear rates was investigated by TEM, observing that in some cases, the dispersed phase was oriented in the direction of flow. A 
relationship between the morphology obtained under different pressure-volumetemperature (PVT) conditions and the mechanical properties was established.

It has been reported that nanoparticles can modify the crystallization temperature and the kinetics of the crystallization process of the polymers [22]. The majority of nanoparticles act as nucleating agents, but in general two effects should be considered: On the one hand, the nucleating effect that increases the crystallization rate and on the other hand, the hindering effect of the nanoparticles on the mobility of the polymer chains that can slow down the crystallization process [22]. Although the effect of nanoparticles has been studied extensively, very few works analyzing the effect of pressure and shear rate on the crystallinity of nanocomposites are reported in the literature. Lin et al. [23] studied PP and PP/CNT nanocomposites under pressures up to 1500 bar and shear rates up to only $201 / \mathrm{s}$ [23]. They analyzed the presence of the gamma crystalline phase and how the different shear rates and pressures modify its content. However, the equipment was not able to measure the crystallization temperature when shear rate and pressure were applied since the authors were only able to perform ex-situ analysis of the sample by X-ray and DSC.

In this work, the combined effect of flow and pressure on the crystallization of nanocomposites and PBNANO's has been studied. We focus in this paper on multiphasic blends containing PP, as the effect of flow on the crystallization of PP is well known. Furthermore, the recent introduction on the market of opaque or white PET bottles (that contain titanium dioxide) has motivated us to study PBNANOs composed of PET, PP and $\mathrm{TiO}_{2}$, which is a model system for recycled bottles, as in many of these white PET bottles the caps are made of PP. For that PP and different nanocomposites, i.e., polypropylene/titanium dioxide $\left(\mathrm{PP} / \mathrm{TiO}_{2}\right)$ and polypropylene/ carbon nanotubes (PP/CNT), have been employed. Furthermore, the study has been extended to PP/PET 80/20 blends and the corresponding PBNANO's containing $\mathrm{TiO}_{2}$ and CNT. As far as the authors are aware, this is the first study with PBNANO's about pressure and flow effects on crystallization. For that purpose, an extended dilatometer, i.e., a PVT device (The Pirouette, see [24].) has been employed that measures the specific volume during cooling and therefore provides a measure for the crystallization temperature. Once the sample has been cooled to room temperature, the samples were removed from the equipment, and the crystalline morphology and crystalline phases formed under different conditions were analyzed employing X-ray analysis and DSC. 
The latter technique was used to first map the nucleating efficiency of the PP based nanocomposites and blends under quiescent conditions.

Overall, this work aims to provide a deeper understanding on the effect of processing conditions on the crystalline morphology and crystalline phases on nanocomposites and PBNANO's which would allow designing materials with desired properties for each application.

\section{EXPERIMENTAL PART}

\section{Materials and blends preparation}

Polypropylene (PP) with a melt flow index of $12 \mathrm{~g} / 10 \mathrm{~min}\left(230^{\circ} \mathrm{C} / 2.16 \mathrm{~kg}\right)$ was supplied by Repsol (ISPLEN PP070G2M), whereas Polyethylene terephthalate (PET) with an intrinsic viscosity of $0.80 \mathrm{dl} / \mathrm{g}$ was provided by Brilen (Novapet CR). The titanium dioxide employed in this work was from io-li-tec nanomaterials with an average diameter of $200 \mathrm{~nm}$ (crystalline form rutile). Multi-wall non-functionalized carbon nanotubes in powder form were obtained from Cheap Tubes Inc. $(D=30-50 \mathrm{~nm}$ and $\mathrm{L}=10-20$ um, purity $>95 \%$ ).

The nanocomposites and blends were prepared in a Collins co-rotating twin screw extruder at $270^{\circ} \mathrm{C}$ and $150 \mathrm{rpm}$. Prior to mixing the CNTs were dried for 2 hours at $100^{\circ} \mathrm{C}$ under vacuum and PET was dried during 2 days at $70^{\circ} \mathrm{C}$. The different systems investigated are shown in table 1.

Table 1. Composition of the different nanocomposites and blends studied in this work.

\begin{tabular}{|l|l|l|l|l|}
\hline Sample & PP* (wt \%) & PET* (wt \%) & $\mathrm{TiO}_{2}(\mathrm{wt} \%)$ & $\mathrm{CNT}(\mathrm{wt} \%)$ \\
\hline $\mathrm{PP}$ & 100 & & & \\
\hline $\mathrm{PP} / \mathrm{TiO}_{2}$ & 100 & & 5 & \\
\hline $\mathrm{PP} / \mathrm{CNT}$ & 100 & & & 5 \\
\hline $\mathrm{PP} / \mathrm{PET}$ & 80 & 20 & & \\
\hline $\mathrm{PP} / \mathrm{PET} / \mathrm{TiO}_{2}$ & 80 & 20 & 5 & \\
\hline $\mathrm{PP} / \mathrm{PET} / \mathrm{CNT}$ & 80 & 20 & & 5 \\
\hline
\end{tabular}

* With respect to the polymeric phase 


\section{Differential Scanning Calorimetry}

Differential Scanning Calorimetric (DSC) experiments were carried out with the samples studied in the PVT device. The first heating scan was analysed, since the aim was to study the crystalline structure of the samples as obtained from the PVT experiments. For that a Perkin Elmer 8500 DSC, calibrated with tin and indium, was used and the measurements were carried out under $\mathrm{N}_{2}$ flow and using $4 \mathrm{mg}$ of sample. The heating scans were performed at $20^{\circ} \mathrm{C} / \mathrm{min}$ from room temperature to $270^{\circ} \mathrm{C}$ in the case of binary blends and PBNANO and to $220^{\circ} \mathrm{C}$ in the case of PP nanocomposites.

\section{Scanning Electron Microscopy and Transmission Electron Microscopy (SEM and TEM)}

The morphology was studied by Scanning Electron Microscopy (SEM) in a Hitachi S-2700 electron microscope with an accelerating voltage of $15 \mathrm{kV}$. The samples were fractured cryogenically and coated with gold employing a Bio-Rad Microscience Division SC500 sputter Coater.

In order to determine the location of the nanoparticles and to analyse the dispersion, a TECNAI G2 20 TWIN (FEI) transmission electron microscope with an acceleration voltage of $200 \mathrm{kV}$ was employed. The samples were cut by ultramicrotomy with a Leica EMFC 6.

\section{Rheological measurements}

Rheological measurements were performed in the linear regime, by means of Small Amplitude Oscillatory Shear tests (SAOS). An ARG2 rheometer, equipped with parallel plates, was used to carry out the frequency sweeps at $180^{\circ} \mathrm{C}$ under nitrogen atmosphere. The same thermal history, as with the PVT experiments, was applied to the samples, see next section.

\section{Dilatometry}

The specific volume of the samples was studied with a Pirouette PVT device (IME Technologies) [24,25]. This equipment allows for analysing the volume of the sample at different pressures, temperatures, cooling rates and shear rates. The central part of the equipment consists of a pressure cell in which a piston die type dilatometer is combined with a Couette rheometer. The following conditions can be applied: pressures from 1 to 1200 bars, shear rates between 1 and 180 1/s, temperatures between 
20 and $300^{\circ} \mathrm{C}$ and cooling rates of (approximately) $0.1,1$ and $90{ }^{\circ} \mathrm{C} / \mathrm{s}$ (average rates measured in the $195-130^{\circ} \mathrm{C}$ temperature range).

Ring shaped specimens obtained by injection moulding in a Babyplast injection moulding machine (Rimbaldi) were employed; dimensions: outer diameter $22 \mathrm{~mm}$, inner diameter $21 \mathrm{~mm}$, thickness $0.5 \mathrm{~mm}$ and height $2.5 \mathrm{~mm}$.

The sample was first heated to $270^{\circ} \mathrm{C}$ and held at this temperature for $5 \mathrm{~min}$ to erase the thermal history. Next, pressure was applied and kept until the sample was cooled down to room temperature. For experiments involving flow, the sample was always cooled at $1{ }^{\circ} \mathrm{C} / \mathrm{s}$ down to $20^{\circ} \mathrm{C}$ and at selected undercooling a shear pulse of $1 \mathrm{~s}$ was applied at respective shear rates of 100 and 180 1/s. Output volumetric data were normalized between temperatures of 200 and $50{ }^{\circ} \mathrm{C}$ for the bimodal materials, and between 240 and $50{ }^{\circ} \mathrm{C}$ for the PBNANO's.

The variation of the normalized specific volume in the melt state, and during the crystallization process is captured by two straight lines. The intersection of these two lines is defined as the crystallization temperature (using the specific volume at 200 ${ }^{\circ} \mathrm{C}$ for bimodal materials and $240{ }^{\circ} \mathrm{C}$ for PBNANOs as the reference). According to Van Erp et al. [14], this crystallization temperature corresponds to a space-filling of about $10 \%$.

After measuring under different processing histories, the samples were removed from the PVT device and stored in a freezer to perform subsequent other analyses, such as X-ray, DSC or SEM and TEM.

\section{X-ray}

Samples have been investigated using a Bruker D8 Discovery system, equipped with a $\mathrm{Cu}$-tube and Montel primary optics employing a $0.2 \mathrm{~mm}$ spot focus size. WAXD analyses were performed with an Eiger2R_500K detector placed at $33.4 \mathrm{~mm}$ from the sample and acquisition time of 120 seconds. WAXD images were backgroundsubtracted before integration. To calculate the crystallinity from the integrated patterns, an amorphous halo, measured on a quenched low tacticity sample with negligible crystallinity, is used by scaling the pattern to the minimum intensity between the (110) and (040) diffraction peaks [26]. The degree of crystallinity is obtained by calculating the ratio between the integrated intensity below the amorphous halo and the total pattern, respectively. The alpha and gamma content fractions were obtained using a deconvolution procedure, where the integrated patterns are considered as a sum of 
several (mostly overlapping) reflections [15, 27]. The relative area below the peaks of the unique crystal reflections was used to determine the fraction of alpha and gamma phase, i.e., the (130) reflection for the alpha phase, and the (117) reflection for the gamma phase [14]. The molecular orientation along the flow direction was obtained from the Hermans orientation factor, calculated via $F_{h}=\left(3<\cos ^{2} \varphi>-1\right) / 2$, where $\left\langle\cos ^{2} \varphi\right\rangle$ is the average cosine squared of the angle between the normal of a given scattering plane and the flow direction. In Figure 1, an example of the 2D WAXD pattern is shown.
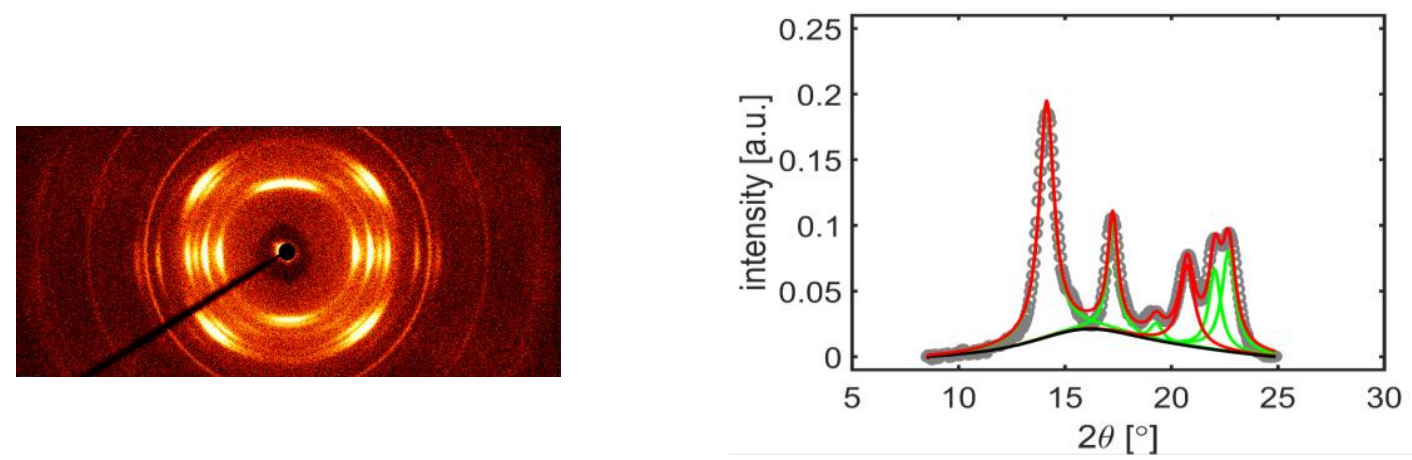

Figure 1. Example of a 2D WAXD pattern of an (oriented) PVT sample (left), with matching integrated curve, showing the amorphous halo and fitting of the individual reflections.

\section{RESULTS AND DISCUSSION}

In this work, six different materials are studied using various experimental techniques. For clarity, in the first section, the characterization of the different systems is analyzed displaying the thermal properties, the dispersion of the nanoparticles, and its location. In the second part, only the dilatometry and X-ray results of four (twocomponent) PP based blends and nanocomposites are discussed. In the third section, the dilatometry and X-ray results of the PP/PET blend and its nanocomposites (PBNANOs) are included.

\section{Characterization of the different systems}

\section{Thermal analysis and nucleating efficiency}

Different nanoparticles, with different nucleating efficiencies, have been selected to study their effect on the crystallization of PP. These complex systems allow us to gain insight into the two factors that affect the crystallization of filled systems under flow: the effect of shear flow and the nucleating effect of the particles. 
In Figure 2, DSC-cooling scans (cooling rate: $0.33{ }^{\circ} \mathrm{C} / \mathrm{s}$ ) for the different systems are shown. Neat PP has a peak crystallization temperature at $113{ }^{\circ} \mathrm{C}$. Incorporation of $\mathrm{TiO}_{2}$ does not change its crystallization temperature. On the contrary, the incorporation of PET and CNTs increases the $T_{c}$ of PP to $118{ }^{\circ} \mathrm{C}$ and $125{ }^{\circ} \mathrm{C}$, respectively. In case of the polymer blends containing nanoparticles, the presence of $\mathrm{TiO}_{2}$ does not alter significantly the $T_{c}$; however the presence of CNTs increases the $T_{c}$ but not as much as in the case of the PP/CNT nanocomposite. This results from the location of the CNTs in the PP/PET blend; as will be explained later, the majority of the nanoparticles are located inside the PET component and only some nanoparticles locate in the PP matrix. In this work, we focus on the crystallization behaviour of PP. Therefore, the DSC scans showing the crystallization of PET are included in the Supporting Information (SI). $T_{c}$ increases only in the presence of CNTs, as can be seen in the SI. Due to the much higher $T_{c}$ of PET as compared to PP, the PET inclusions can be considered as solid filler particles during the crystallization of PP.

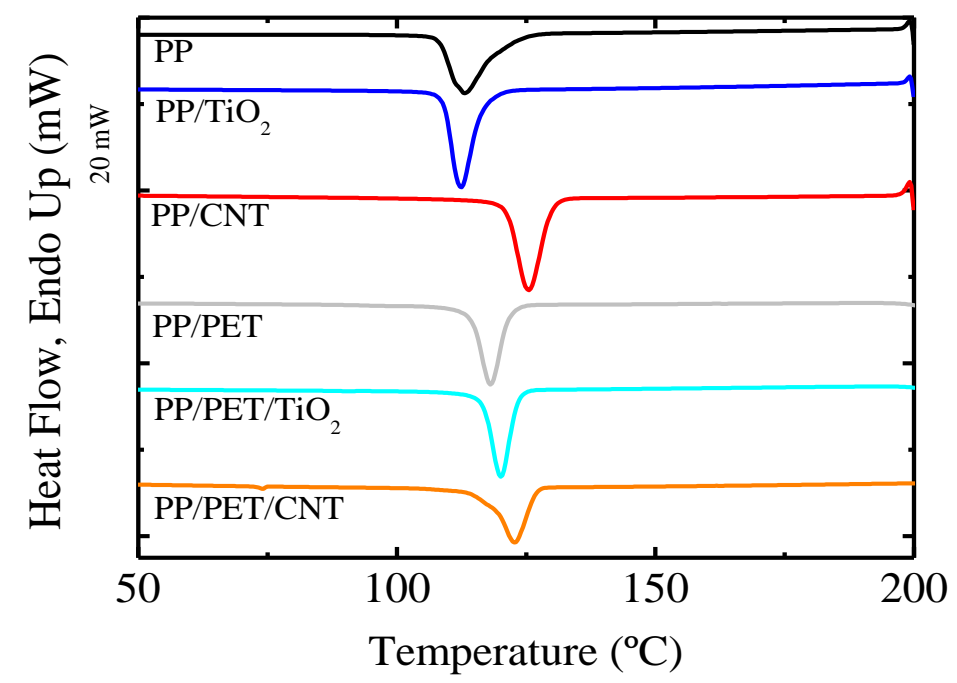

Figure 2. Cooling scans for the nanocomposites and polymer blends containing different nanoparticles.

To quantify the nucleating efficiency, NE, the following expression $[28,29]$ has been applied (the details of the self-nucleation procedure are presented in the Supplementary Information):

$$
N E=\frac{T_{C, \text { sample }}-T_{c, \text { standard thermal history }}}{T_{c, \text { self }- \text { nucleated sample }}-T_{c, \text { standard thermal hystory }}} X 100
$$




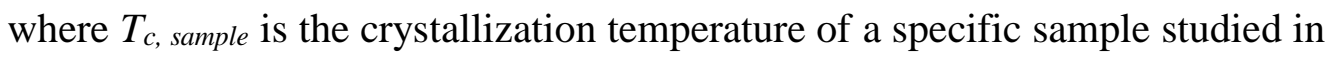

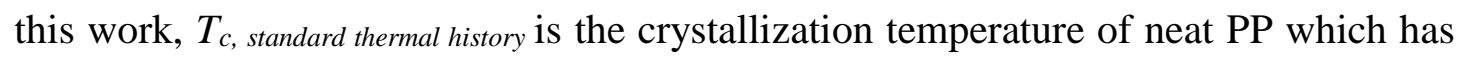
been completely molten and then crystallized during cooling with a set cooling rate (i.e., "standard thermal history"), and finally $T_{c}$, self-nucleated sample is the crystallization temperature, obtained after self-nucleating the sample at the minimum self-nucleation

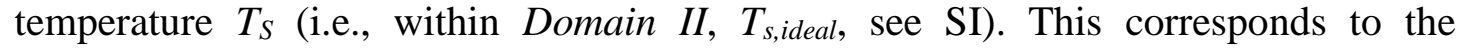
temperature that generates the maximum number of self-nuclei without annealing (see refs. [28,29]).

The nucleating efficiencies for the different samples are presented in Table 2. It can be observed that $\mathrm{TiO}_{2}$ does not act as a nucleating agent, which has been already reported in the literature [30] and results from the surface properties of the $\mathrm{TiO}_{2}$. On the other hand, PET has an intermediate nucleating efficiency, and CNTs show the highest nucleating efficiency. The surface area to volume ratios should be considered to understand the different nucleating efficiency levels of PET droplets and CNTs. For PET droplets a surface area to volume ratio of $5.9510^{5} 1 / \mathrm{m}$ is calculated from the average droplet size of $d_{v}=10.74 \mu \mathrm{m}$, whereas for nanotubes a much higher value is obtained, $1.010^{8} 1 / \mathrm{m}$, as could be expected due to its high aspect ratio. Although the content of PET is $20 \%$ in weight, four times higher than the content of CNTs in the samples (5\% in weight), the surface area to volume ratio is almost three orders of magnitude higher for CNTs than for PET. Therefore, since there is much more surface area available that can act as nucleation sites, the nucleating efficiency should be higher for the PP which contains CNTs, i.e., for the PP/CNT nanocomposite.

In the case of blends containing nanoparticles, $\mathrm{PP} / \mathrm{PET} / \mathrm{TiO}_{2}$ shows a slightly higher nucleating efficiency than PP/PET, whereas when CNTs are added, the value rises to $48 \%$. As explained before, the nucleating efficiency is lower in this case than in the PP/CNT nanocomposite because the CNTs are only partly located in the PP matrix.

Table 2. Nucleating efficiency for the different samples studied in this work.

\begin{tabular}{|c|l|}
\hline Sample & Nucleating efficiency (\%) \\
\hline
\end{tabular}




\begin{tabular}{|l|l|}
\hline $\mathrm{PP} / \mathrm{TiO}_{2}$ & 0 \\
\hline $\mathrm{PP} / \mathrm{PET}$ & 27 \\
\hline $\mathrm{PP} / \mathrm{CNT}$ & 67 \\
\hline & \\
\hline $\mathrm{PP} / \mathrm{PET}$ & 27 \\
\hline $\mathrm{PP} / \mathrm{PET} / \mathrm{TiO}_{2}$ & 37 \\
\hline $\mathrm{PP} / \mathrm{PET} / \mathrm{CNT}$ & 48 \\
\hline
\end{tabular}

These systems allow us to study: a) The effect of shear in the presence of particles that do not have a nucleating effect on the matrix, as is the case for the $\mathrm{PP} / \mathrm{TiO}_{2}$ system and b) The combined influence of the shear rate and the nucleating effect for $\mathrm{PP} / \mathrm{PET}$ and PP/CNT systems, that have a different nucleating efficiency.

\section{Dispersion of the nanoparticles}

An important aspect for nanocomposites is the degree of dispersion of the nanoparticles since this determines structure development and final properties. As can be observed in Figure 3 a) in the case of $\mathrm{PP} / \mathrm{TiO}_{2}$ nanocomposites, nanoparticles tend to aggregate in the PP matrix and, at this high magnification, it can be observed that these nanoparticles do not form a percolated network. However, in the case of PP/CNT nanocomposites (Figure 3 b)), it can be observed that the CNTs are very well dispersed, being able to form a network.

a)

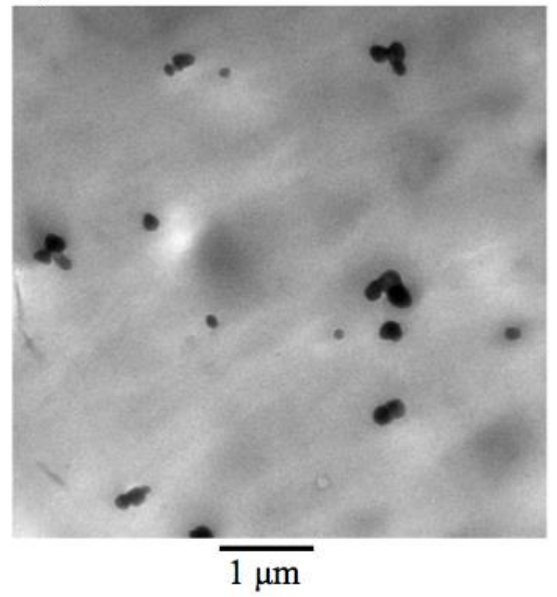

b)

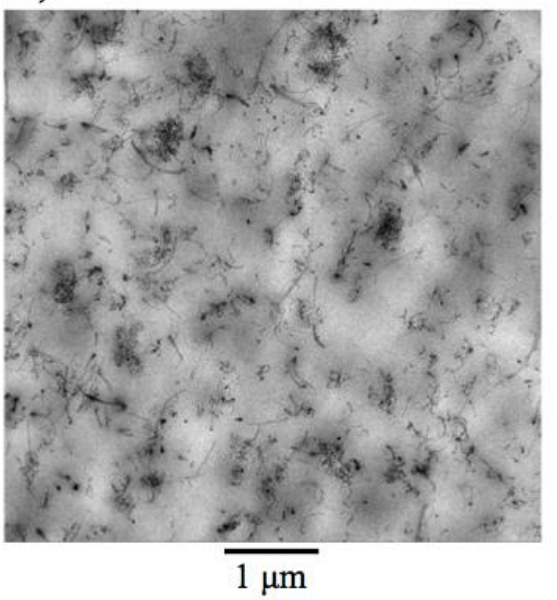

Figure 3. TEM micrographs of a) $\mathrm{PP} / \mathrm{TiO}_{2}$ nanocomposite and b) $\mathrm{PP} / \mathrm{CNT}$ nanocomposite.

Morphology and localization of nanoparticles in the blends 
The study of the effect of shear rate and pressure on the crystallization of PP based materials has been extended to more complex systems, such as binary blends containing nanofillers, the so-called polymer blend nanocomposites, PBNANO's. First, the blend morphology and the location of the nanoparticles is studied. The PP/PET binary blends show a droplet-matrix morphology in the presence or absence of nanoparticles. The presence of $\mathrm{TiO}_{2}$ does not change significantly the droplet size (for PP/PET $10.7 \mu \mathrm{m}$ whereas $12.3 \mu \mathrm{m}$ is obtained for PP/PET/TiO 2 ), however, when CNTs are added the size is reduced significantly $(6.0 \mu \mathrm{m})$. The corresponding morphologies of the samples have been studied by SEM imaging after applying different conditions in the PVT experiments, showing that the differences are negligible. The reason for this is that, when shear is applied, the PET droplets are already crystallized.

As can be seen in Figure 4 a), the $\mathrm{TiO}_{2}$ nanoparticles in $\mathrm{PP} / \mathrm{PET} / \mathrm{TiO}_{2}$ PBNANOs are located in the PP phase, at the interface, and in the PET droplets. In principle, the more favored location should be the PET phase due to thermodynamic reasons, as has been reported in the literature for a similar system [31]. However, due to the high viscosity of the polymers involved, the $\mathrm{TiO}_{2}$ nanoparticles do not have time enough to reach the thermodynamically more favored phase, thereby remaining partially in the PP phase.

In the case of PP/PET/CNT PBNANOs, a similar result is obtained (see Figure $4 \mathrm{~b}$ ), CNTs tend to localize inside the PET droplets and at the interface and some CNTs are also observed in the PP phase. This is the expected behavior since CNTs have polar groups on the interface, and thus, they tend to go to the PET phase that is hydrophilic [32]. 
a)

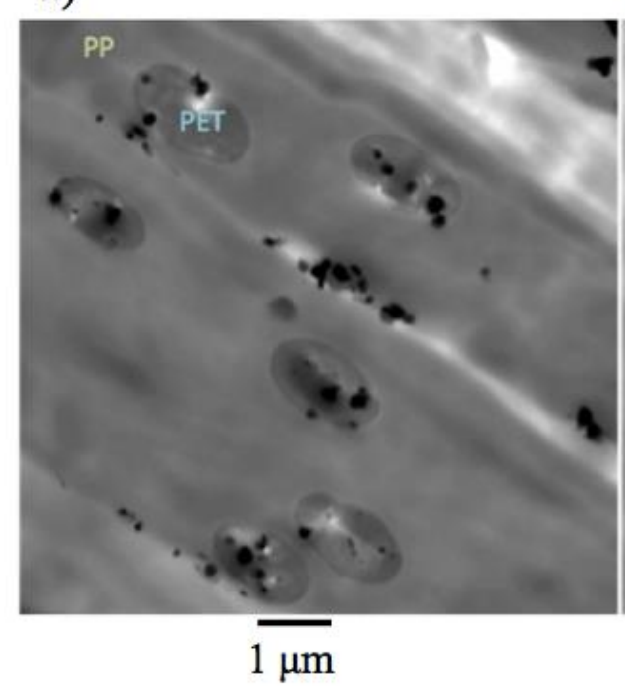

b)

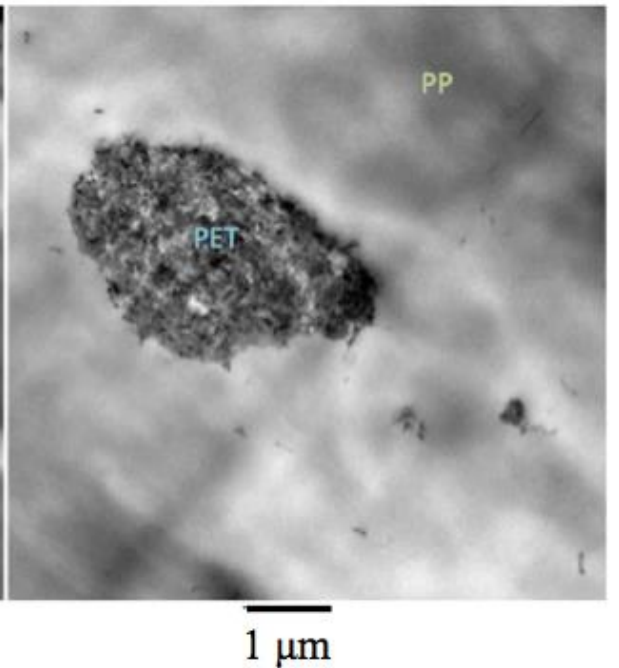

Figure 4. TEM micrographs of a) $\mathrm{PP} / \mathrm{PET} / \mathrm{TiO}_{2} \mathrm{PBNANO}$ and b) $\mathrm{PP} / \mathrm{PET} / \mathrm{CNT}$ PBNANO.

\section{Rheological properties}

The linear viscoelastic rheological measurements give a sound picture of the dispersion level of the different nanoparticles. Pure polymers show a viscous-like behavior, characterized by $G$ ' $>\mathrm{G}$ ', in the terminal zone, i.e., in the low-frequency range. However, when nanoparticles are properly added, at a certain concentration, a percolated network, based on particle-particle and/or particle-chain interactions, is formed. This network gives rise to an elastic-like response, which at low frequencies is characterized by a plateau of the elastic modulus, G', with $G^{\prime}>G^{\prime \prime}$ [33]. According to our results for the $\mathrm{PP} / \mathrm{TiO}_{2}$ nanocomposite, there is no indication of a percolated network since the terminal zone shows viscous-like behavior, with $G$ ' ' $>G$ ', see Figure 5. The behaviour is similar to that observed for the PP/PET blend, although in the latter there is a slight increase of the elastic modulus which results from the elastic component of the polymer-polymer interface $[34,35]$. In the case of the PP/CNT nanocomposite, the rheological behavior at low frequencies (terminal zone) changes completely: The elastic modulus exceeds the viscous modulus, and a G' plateau is observed. As stated above, this indicates that a percolated network has been formed in the PP/CNT nanocomposite, which contains well dispersed 5\% CNTs.

A similar rheological trend as observed for the PP based nanocomposites is found for the PP/PET blend based nanocomposites, PP/PET/TiO 2 , and PP/PET/CNT PBNANOs: The addition of $\mathrm{TiO}_{2}$ does not change the viscous-like rheological behavior of the blend. Instead, when CNTs are added, an elastic-like response is observed. The 
fact that the low-frequency G' value for the PP/PET/CNT blend is lower than that of the PP/CNT nanocomposite suggests that part of the CNTs is localized in the PET droplet phase of the blend in agreement with TEM results, resulting in a lower effective nanoparticle concentration in the PP matrix.
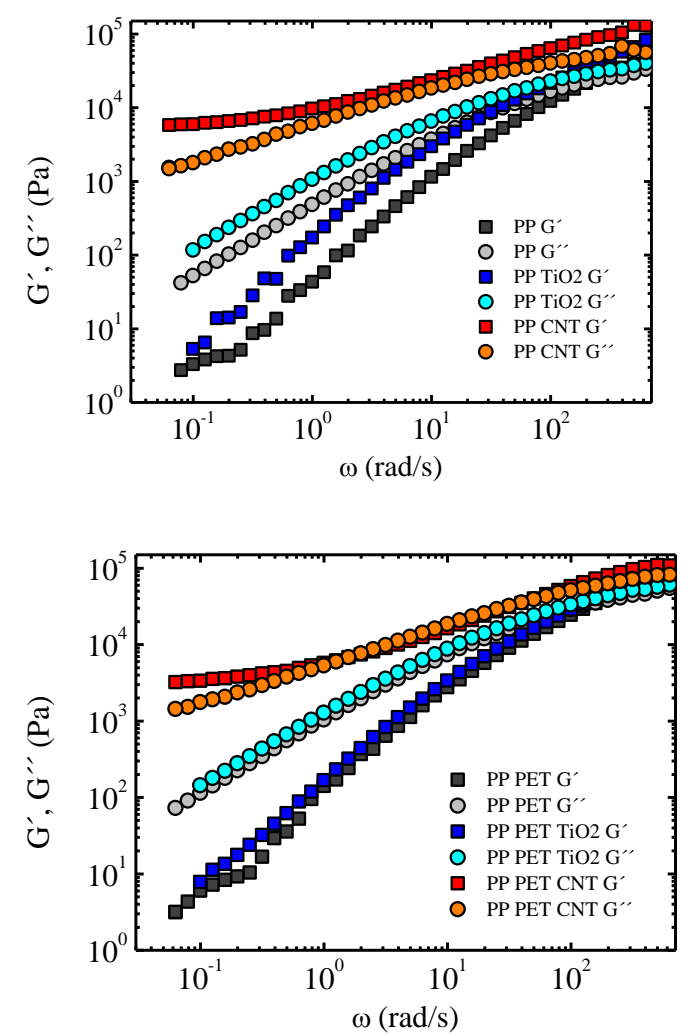

Figure 5. Elastic and loss moduli against frequency for the different systems studied in this work at a temperature of $180^{\circ} \mathrm{C}$.

\section{PP, PP/TiO2, PP/PET and PP/CNT nanocomposites or blends}

\section{Dilatometry}

The variation of the specific volume with temperature under different pressures and applied shear rates has been studied in order to gain insight into the crystallization behavior of the materials. In Figure 6, the normalized specific volume of the different samples during cooling from the melt is shown; a continuous decrease of the volume is observed at high temperatures due to thermal shrinkage. As a consequence of crystallization, a drastic volume drop is observed for pure PP at $120^{\circ} \mathrm{C}$ for a pressure of $100 \mathrm{bar}$, and at $150^{\circ} \mathrm{C}$ for a pressure of $1200 \mathrm{bar}$, see Figure $6 \mathrm{a}-\mathrm{b}$. This can be explained by the fact that crystallization is driven by undercooling: 


$$
\Delta T=T_{m}^{0}(p)-T_{c}
$$

with $\Delta T$ the undercooling, $T_{m}{ }^{o}(p)$ the equilibrium melting point under pressure and $T_{c}$ the crystallization temperature of the sample. When pressure is applied the equilibrium melting point increases, thus the same undercooling is obtained at higher crystallization temperatures [14].

The PVT device used allows studying the effect of pressure and the effect of applied shear simultaneously. A shear pulse is applied for 1 second at a given undercooling. Hence, for a cooling rate of $1^{\circ} \mathrm{C} / \mathrm{s}$, the temperature change during the pulse is negligible. Two shear rates have been applied, 100 and 180 1/s, at two different undercooling values, 30 and $60^{\circ} \mathrm{C}$ (for further information about the calculation of the temperature at which shear is applied see Supporting Information). When shear is applied, it can be observed that there is a dip (see the arrow in Figure 6) in the specific volume. This is not considered any further since it is an artifact. The data corresponding to samples in the solid state are not accurate, since for piston die equipments the pressure is not hydrostatic for solid samples. Therefore, the results corresponding to the solid region are not considered.

The consequence of applying a shear rate is an increase in the crystallization temperature, which is more pronounced at high undercooling or higher shear rates. The enhancement of the crystallization temperature is explained, considering that the number of nuclei increases when shear is applied, by provoking segmental orientation $[14,36,37]$. In some cases, the normalized specific volume shows a negative value at temperatures below the crystallization regime. This follows from the choice of the lowest normalization temperature and limited friction occurring between the sample and the device at such low temperatures, and it is not considered of importance in this investigation. 
a)

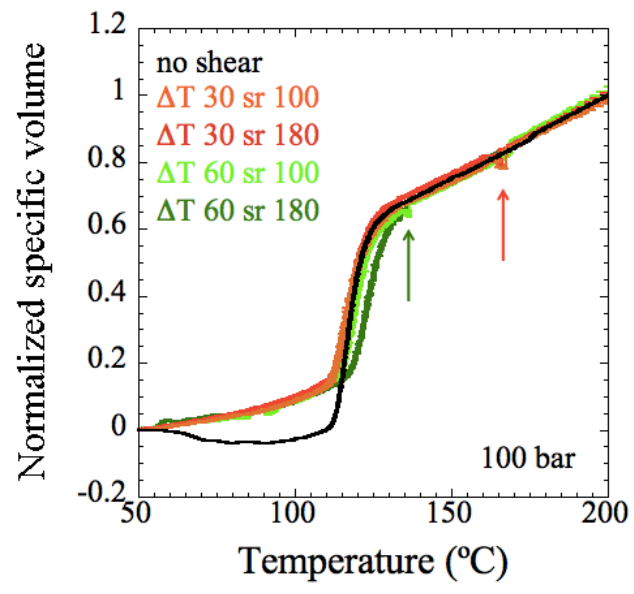

c)

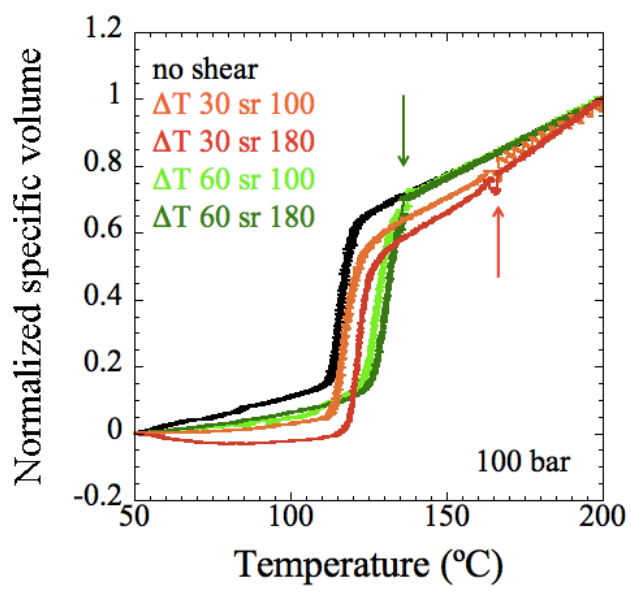

e)

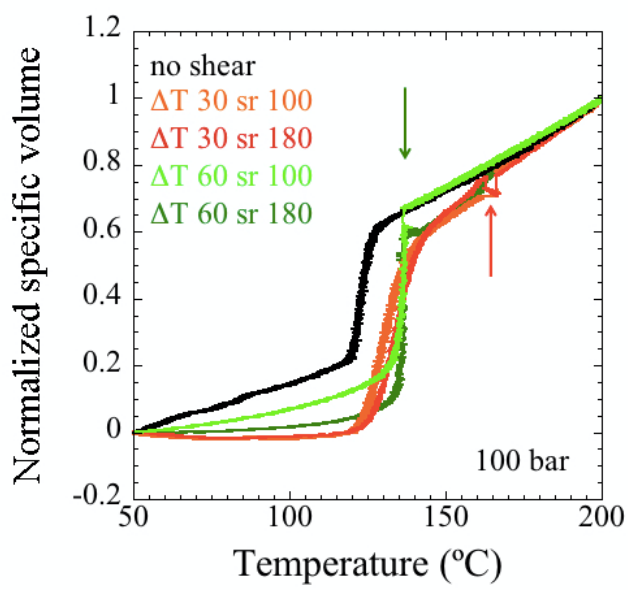

b)

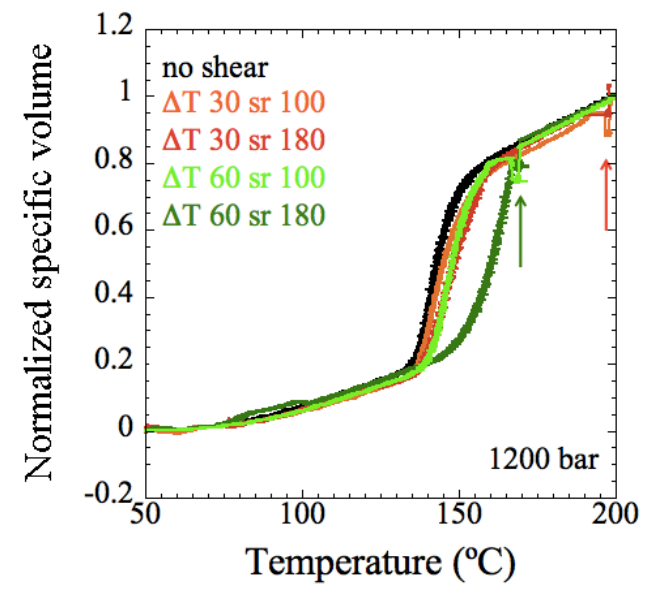

d)

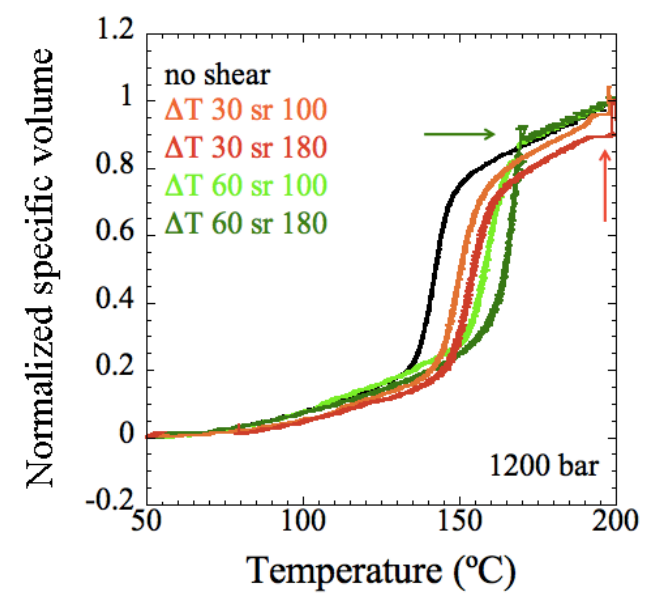

f)

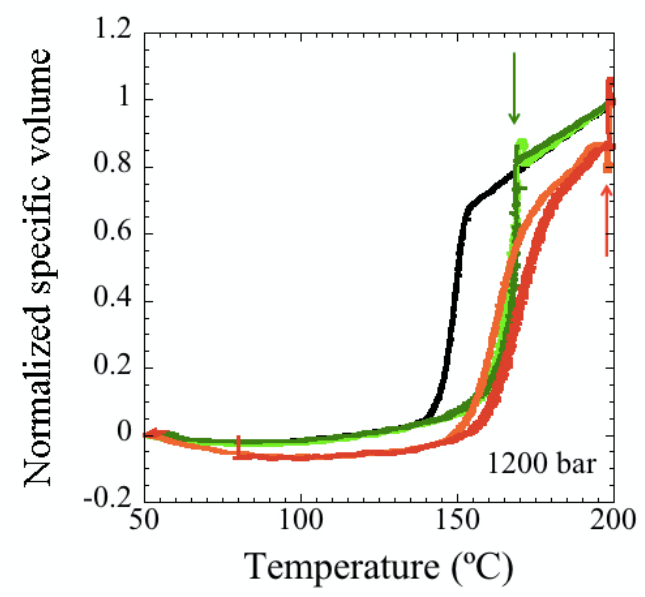


g)

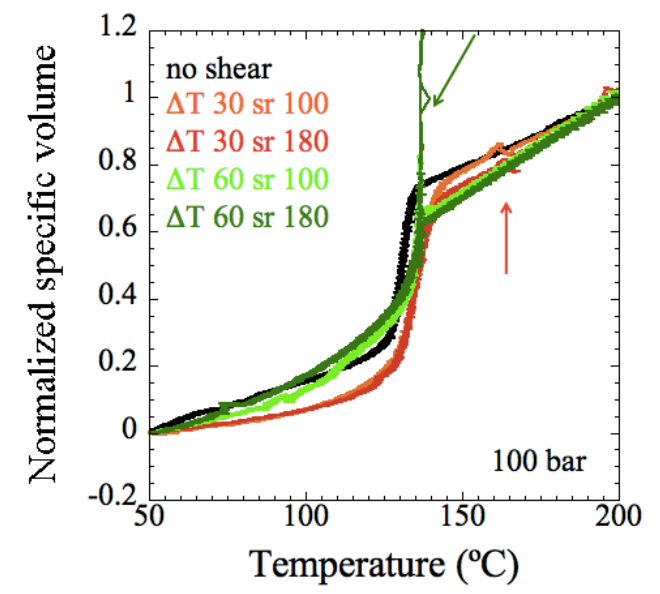

h)

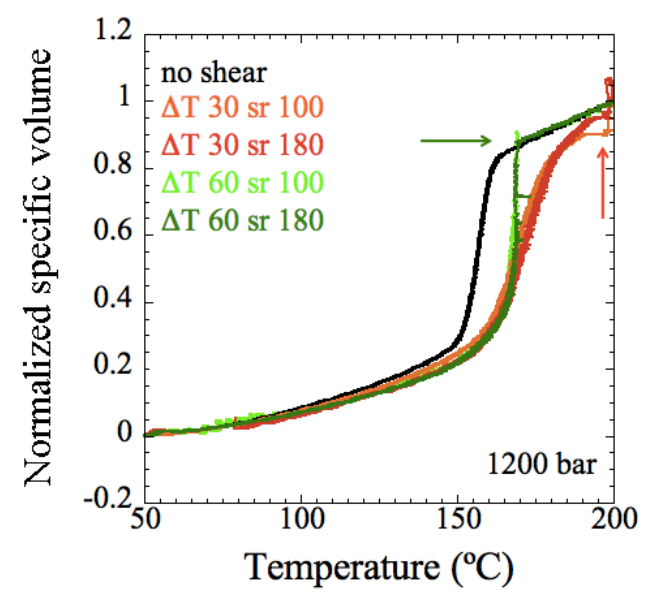

Figure 6. The normalized specific volume measured during cooling from the melt for PP (a and b), PP/TiO 2 (c and d), PP/PET (e and f) and PP/CNT (g and h) at different conditions. The arrow marks the artifact due to the shear pulse.

To quantify the effect of pressure and shear rate on the crystallization temperature, the normalized crystallization temperature is employed, which is defined by:

$$
\theta=\frac{T_{C}^{\dot{\gamma}}}{T_{C}^{Q}}
$$

i.e., the ratio between the crystallization temperature of the sample submitted to pressure and shear rate and the crystallization temperature of the same sample under quiescent conditions [14]. The variation of $\theta$ with pressure at different shear rates is presented in Figure 7. The measurements are reproducible; the error is around 1\%, so the error bars of this parameter are smaller than the symbols in the figure. At intermediate and high pressures (100 and 1200 bar), the relative crystallization temperature of PP increases with the applied shear rate.

From a molecular point of view, the increase of the crystallization temperature due to shear is explained by considering that during shear, the molecules are oriented in the direction of flow. The low molecular weight chains relax fast, whereas long chains do relax much slower, allowing forming stable nuclei [38]. When pressure is applied to the sample, the polymer chains are more closely packed in the melt, resulting in a decrease of the nucleation barrier and enhanced formation of nuclei [14]. Moreover, the relaxation time (and thus the viscosity) is increased, which causes the effects of flow to become stronger, i.e. slower relaxation of the molecular chains. 
It can be observed that the presence of $\mathrm{TiO}_{2}$ results in an enhancement of the effect of shear rate, as the increase of the $\theta$ parameter is more significant, see Figure 7. As has been explained above, $\mathrm{TiO}_{2}$ does not act as a nucleating agent under quiescent conditions. However, when shear is applied the crystallization temperature increases more significantly than for pure PP, i.e., there is an amplification of the effect of flow. This effect has been reported in the literature for other nanocomposites $[39,40]$. There are several hypotheses to explain the effect of shear flow in the presence of nanoparticles. According to Wang et al. [41], nanoparticles reduce the mobility of chains, thus the relaxation time of the chain increases, which favors the formation of nuclei. Jay et al. [42] reported that, although the polymer is submitted to a shear flow, the presence of particles results in local extensional flow as the polymeric chain is deposited on a solid surface. It is well known that extensional flow is more efficient in inducing crystallization than shear flow [15, 43]. Hwang et al. [44] performed numerical simulations on systems containing particles under shear flow, confirming that the polymer chains are stretched between two particles.

The increase of the pressure applied to the $\mathrm{PP} / \mathrm{TiO}_{2}$ sample increases the $T_{c}$. This is caused, as mentioned before, by the increase of the equilibrium melting point and thus the same undercooling is obtained at higher temperatures.

In the case of PP/PET and PP/ CNT systems, both the PET phase and the CNT nanofillers act as nucleating agents. Therefore when shear flow is applied there are two effects: the effect of heterogeneous nucleation and the effect of flow. This is elaborated further in the following paragraphs.

Under quiescent conditions, for PP/PET blends, the presence of PET crystalline particles increases the $T_{c}$ of the PP phase with about $5^{\circ} \mathrm{C}$ (Figure 2). Under shear flow, the increase of $T_{c}$ is more pronounced for the binary blend than for PP as can be seen in Figure 7. This can be explained by the combined effect of nucleation mentioned before and the PET particles provoking stretching of the PP polymer chains near the surface of the droplets [45].

Contrary to what is obtained for $\mathrm{PP}$ and $\mathrm{PP} / \mathrm{TiO}_{2}$, increasing pressure in the case of the PP/PET blend yields a $T_{c}$ that is similar, regardless of the applied pressure at low undercooling. However, at high undercooling, there is an increase in $T_{c}$ with pressure, showing a similar trend to that of the $\mathrm{PP} / \mathrm{TiO}_{2}$ nanocomposites. This behaviour differs 
from that of $\mathrm{PP}$, in which the effect of pressure at high undercooling is not very significant.

In the case of the PP/CNT nanocomposite, when shear rate is applied at low undercooling, the crystallization temperature increases significantly, due to the combined effect of the nucleation and shear flow. On the other hand, when the shear rate is applied at higher undercooling, the increase of $T_{c}$ is really small; in some cases even less significant than in pure PP. This is, first of all, caused by the already strongly increased $T_{c}$ due to the CNT nucleation and thus the shear temperature is nearly the same as $T_{c}$. The effect of flow is mainly in speeding up the crystallization kinetics. One can question the usefulness of the normalized crystallization temperature in this case and could think about another more meaningful parameter.

Analyzing the crystallization temperature vs. pressure, the slope does not change significantly for the different samples; only a slight decrease is observed for the PP/PET blend. Therefore, contrary to the effect observed with shear and particles, where a synergistic effect was found, when pressure is applied the presence of nanoparticles or PET phase does not alter significantly the response of the material.

If the different systems are compared, it is observed that at low undercooling the highest increase of the $\theta$ parameter is obtained for both, PP/CNT and PP/PET nanocomposites, whereas at high undercooling the highest increase is reached for the PP/PET blend $(\theta=1.2)$. From PVT data, obtained under a pressure of 100 bar, the $\mathrm{PP} / \mathrm{CNT}$ nanocomposite has a higher $T_{c}\left(134.5^{\circ} \mathrm{C}\right)$ than the PP/PET blend $\left(T_{c}\right.$ $=127.12^{\circ} \mathrm{C}$ ), which means that CNTs are more efficient nucleating agents. However, when shear is applied at low undercooling similar $T_{c}$ values are obtained, indicating that the effect of flow is more pronounced in the blend. These results indicate that there is a saturation of the number or density of nuclei. For PP/CNT, there are more heterogeneous nuclei than flow-induced nucleation sites as a consequence of the high nucleating efficiency of CNTs. However, in the case of the PP/PET blend, it seems that the increase in $T_{c}$ results from the higher amount of flow-induced nuclei, as the nucleation efficiency of PET is lower than that of CNTs. The more significant enhancement of the crystallization due to flow in the PP/PET blends may be caused by the higher fraction of solid PET inclusions as compared to $\mathrm{TiO}_{2}$ particles. This results in a larger effective shear rate in the PP matrix due to the fact that the solid inclusions cannot undergo any shear deformation. 
D'Haese et al. [45] studied the influence of flow on the crystallization of PP filled with zinc oxide, analyzing the effect of the size and geometry of the filler. They observed that at relatively low shear rates (less than 200 1/s) the nucleating effect of the particles governs the crystallization. However, at higher shear rates (200-400 1/s), the crystallization is governed by the flow, and the effect of fillers is negligible. In our work, the results are extended to more complex systems, including different nanoparticles and blend nanocomposites.

In brief, the results show that the presence of nanoparticles that do not act as nucleating agents increases the crystallization temperature under shear rate, due to the local flow generated between particles. When the combined influence of nucleating effect due to particles and flow takes place, the increase in the crystallization temperature is even more pronounced. This is the case when there are heterogeneous nuclei generated due to the presence of the nanoparticles and homogeneous nuclei promoted by the flow.

a)

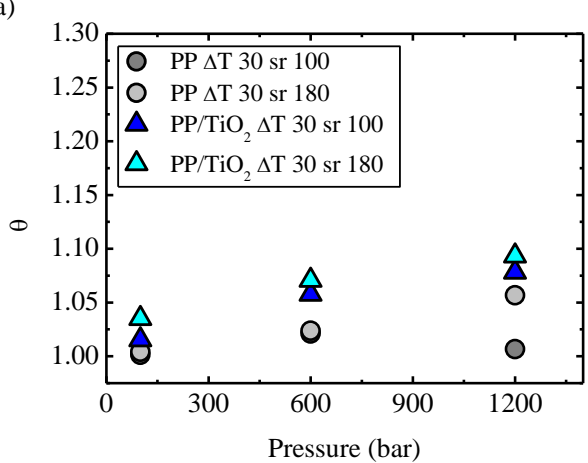

c)

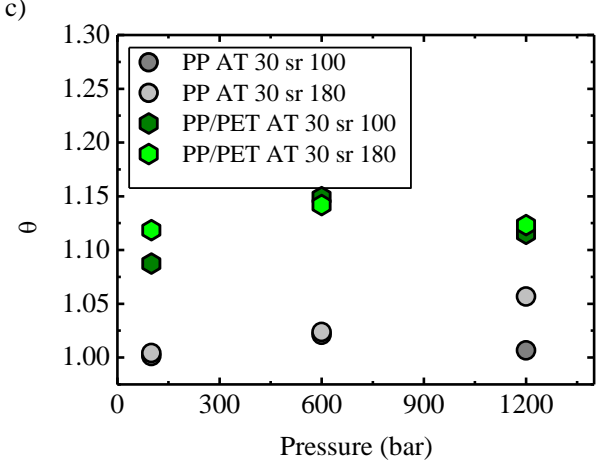

b)

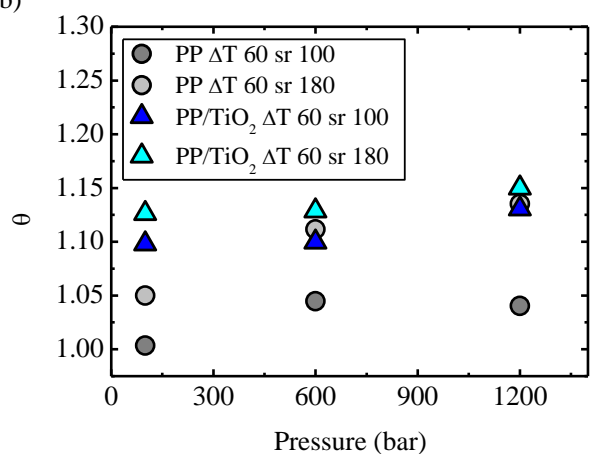

d)

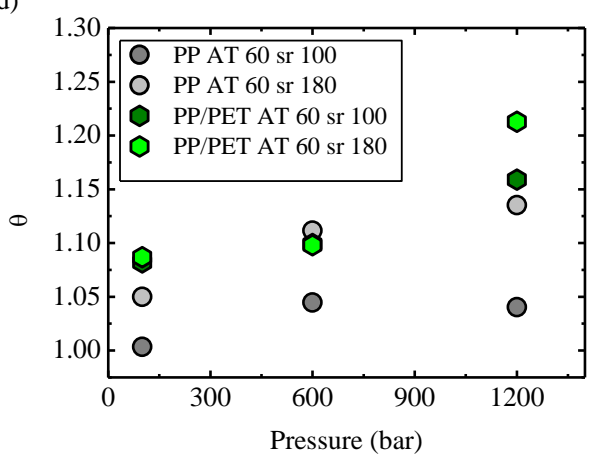



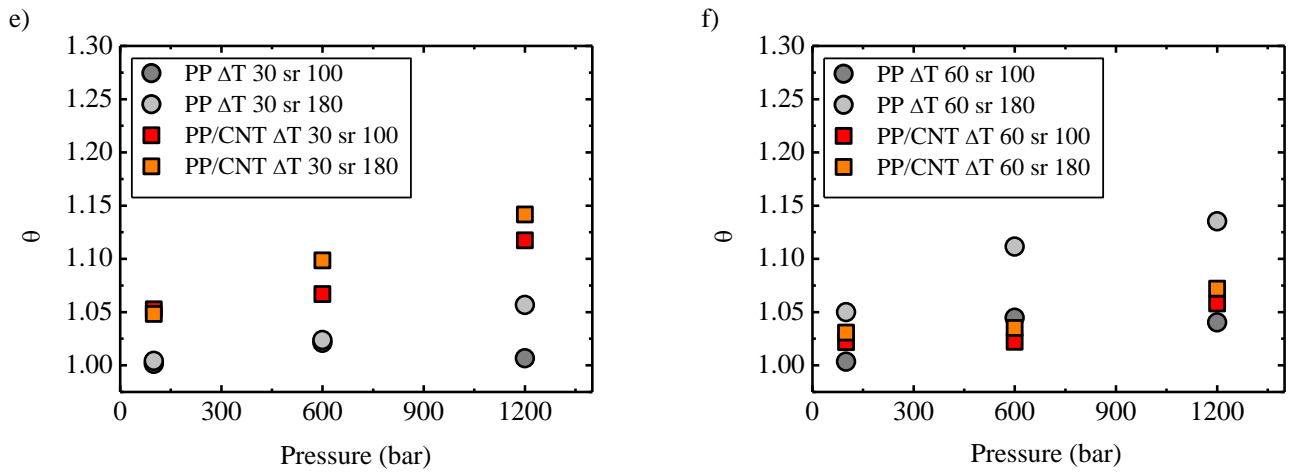

Figure 7. $\theta$ parameter defined in the text, as a function of pressure for PP, $\mathrm{PP} / \mathrm{TiO}_{2}$ (a and b), PP/PET ( $\mathrm{c}$ and d) and PP/CNT (e and f) at the indicated shear rates.

\section{Orientation and crystal phases}

To study the effect of flow on the orientation of the PP chains, WAXD studies were performed. Only the samples submitted to high pressures (1200 bar) and flow have been studied. WAXD results show that under these conditions only alpha and gamma phase is created, as could be expected from the results reported in the literature [14]. The orientation of alpha and gamma crystals has been procured from WAXD data, and the results are shown in Figure 8. If the data of the orientation are analyzed, it can be seen that there is no orientation in the absence of flow, as expected.

When shear flow is applied for PP and $\mathrm{PP} / \mathrm{TiO}_{2}$, it can be observed that at low undercooling there is practically no orientation because the chains have time to relax, so the crystals are isotropic. However, for PP/PET and PP/CNT systems, orientation of the crystals is observed: interestingly these are the two systems in which the second component (PET and CNT respectively) acts as a nucleating agent. In the case of $\mathrm{PP} / \mathrm{CNT}$, the orientation is more significant, and it is observed at low and high undercooling. This is compatible with the stronger interactions between the PP chains and the CNTs, as compared to its interactions with PET, which has already been noted from the rheological measurements in Figure 5. Due to these interactions, the samples retain their orientation, since the relaxation time is longer, hindering the disorientation of the crystals.

At high undercooling, it can be observed that all the samples show orientation, except for the PP/PET blend. The lack of crystal orientation for the PP/PET blend at high undercooling is unexpected and we do not have a satisfactory explanation for this. 
For the other samples, the observed orientation is particularly high for the gamma phase in the nanocomposites. This is explained considering that since the shear pulse is applied at lower temperatures, the relaxation time, and thus the viscosity, increases, hindering the disorientation of the crystals, which leads to a high density of flow enhanced nucleation sites. Moreover, the nanoparticles that also act as nucleation sites are also oriented by the flow. This strong increase in nucleation sites causes the growth of more gamma phase in the limited temperature range where gamma dominates the alpha phase $[13,14]$ and this gamma fraction is oriented.
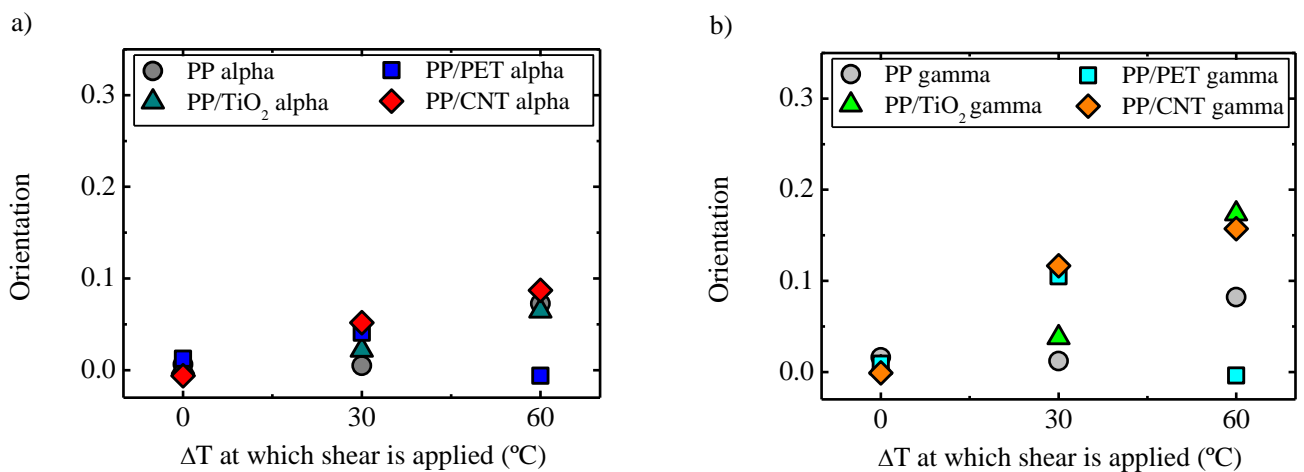

Figure 8 . The orientation of the a) alpha and b) gamma crystals for the different PP based systems for the samples summited to 1200 bar and applying shear (at two different undercoolings, $\Delta \mathrm{T}=30$ and $\left.60^{\circ} \mathrm{C}\right)$ or without shear $\left(\Delta \mathrm{T}=0^{\circ} \mathrm{C}\right.$ in the $\mathrm{x}$-axis $)$.

The crystallinity of the PP fraction in the samples and the content of each crystalline phase have been calculated from X-ray data. The total PP crystallinity of the samples is shown in Figure 9. When shear is applied there is a slight increase in the crystallinity. In the case of $\mathrm{PP}$ and $\mathrm{PP} / \mathrm{TiO}_{2}$ nanocomposite the crystallinity increases when shear is applied at high undercooling, whereas for PP/PET and PP/CNT, it increases at low undercooling. These results are in agreement with the increase of $T_{c}$ observed by the PVT technique.

From WAXD data, the amount of each crystal phase can be analyzed, as is shown in Figure 9. In the absence of shear and under a pressure of 1200 bar a higher content of gamma phase than alpha phase is observed for all samples. As reported by Van Erp et al. [14], the ratio of the growth rate of gamma phase over that of the alpha phase is slightly higher than 1 at 100 bar, but when the pressure is increased to 1200 bar this ratio is doubled; therefore more gamma phase crystals should be created than alpha phase crystals. According to Yang et al. [46], three factors promote the formation 
of the gamma crystal form: high pressure, the relaxed conformation of chains, and an oriented alpha nucleus. In the case of pure PP, when shear rate is applied at low undercooling the content of gamma phase increases significantly. Following Yang et al., one could reason that the chains have time to relax and disorient and thus allow gamma crystals to be formed. However, also the increased nucleation density generates more gamma at relatively high temperature and can explain the larger amount of gamma; see also the discussion before on the oriented gamma phase. For $\mathrm{PP} / \mathrm{TiO}_{2}$, PP/PET and PP/CNT systems similar results to those obtained under quiescent conditions are achieved, likely because chains have time to relax.

Changing the conditions to high undercooling, similar results to those of the quiescent state are obtained for PP and PP/TiO 2 . However, both PP/PET and PP/CNT show more alpha phase than gamma phase. This can be explained considering that at high undercooling shish kebab structures are likely formed and the chain orientation promotes the growth of alpha phase kebab due to the increased growth rate of these kebabs, see [17]. This reduces the amount of gamma phase. The formation of such oriented crystalline structures could be confirmed by 2D SAXS images, based on the intense streaks close to the beamstop.

In the Supporting Information, the DSC heating scans are shown and the different crystal phase contents obtained from DSC are compared with X-ray results.

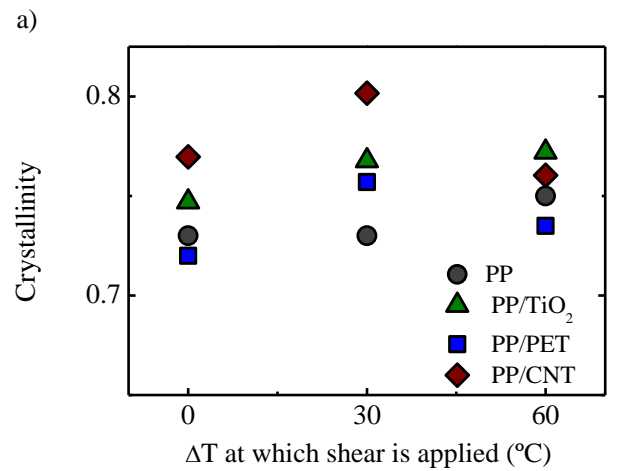



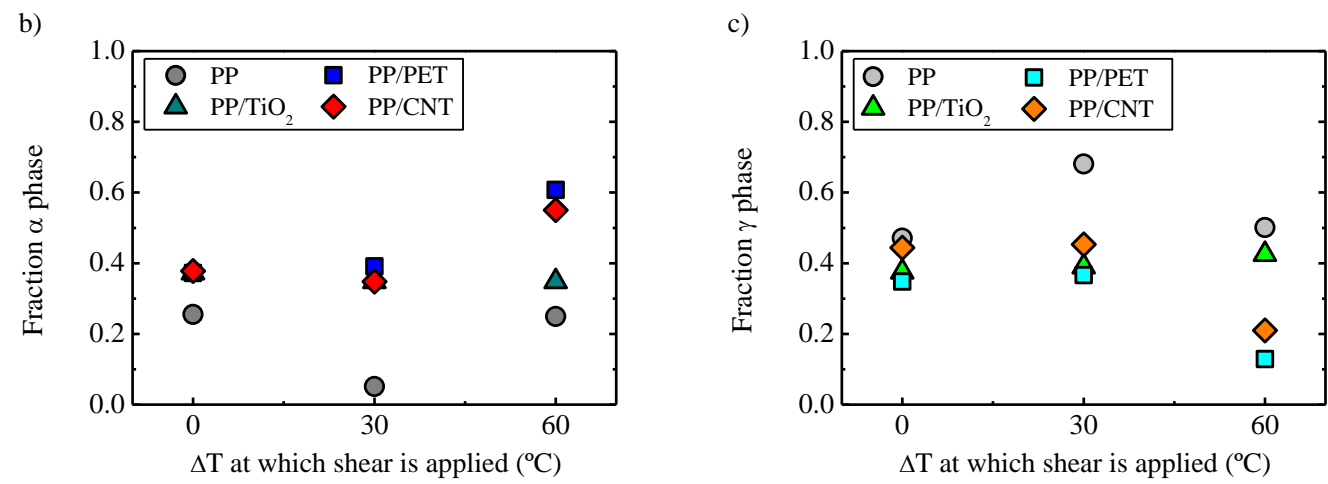

Figure 9. a) Total crystallinity of PP and its nanocomposites and fraction of $b$ ) alpha and c) gamma crystalline phases for the samples summited to 1200 bar, without shear $\left(\Delta \mathrm{T}=0{ }^{\circ} \mathrm{C}\right.$ in the $\mathrm{x}$ axis) and with applying a shear rate of $1801 / \mathrm{s}$ at 2 different undercoolings $\left(\Delta \mathrm{T}=30\right.$ and $\left.60^{\circ} \mathrm{C}\right)$.

\section{PP/PET Polymer Blend and its Nanocomposites (PBNANOs)}

\section{Dilatometry}

In this section, the PVT results for the PP/PET blend, as well as for nanocomposites based on this blend, called PBNANO's are discussed. In Figure 10, the PVT curves of the PP/PET blend, the blend containing $\mathrm{TiO}_{2}\left(\mathrm{PP} / \mathrm{PET} / \mathrm{TiO}_{2}\right)$ and the blend containing CNTs (PP/PET/CNT) are shown. At the lowest pressure, 100 bar, a small shoulder (signaled with an arrow in Figure 10a) which corresponds to the crystallization of the PET is observed, notwithstanding it has not been possible to determine the $T_{c}$ value in a reliable way due to the small signal. At higher pressures, this shoulder disappears, because PET crystallizes faster, probably as soon as pressure is applied to the molten sample. Due to the limitations of the equipment, it was not possible to increase the temperature to study the crystallization of PET. Therefore, only the effect of PET and fillers on the crystallization of PP is studied.

In literature it has been reported that at atmospheric pressure PET crystallizes at about $185^{\circ} \mathrm{C}$ at $1^{\circ} \mathrm{C} / \mathrm{s}$ [47], thus, at the temperatures at which the shear rate is applied, 168 and $138^{\circ} \mathrm{C}$, PET is already crystallized. According to our results, the crystallization temperatures determined from DSC and PVT differ. From PVT data, for an average cooling rate of $1^{\circ} \mathrm{C} / \mathrm{s}$, it is seen that $\mathrm{PP}$ crystallizes at about $124^{\circ} \mathrm{C}$, see Figure $6 \mathrm{a}$, 
whereas from DSC at a cooling rate of $20^{\circ} \mathrm{C} / \mathrm{s}$ it crystallizes at $113^{\circ} \mathrm{C}$. It should be noted that DSC works under atmospheric pressure whereas the measurement of the PVT was obtained at 100 bar. This pressure difference could explain a shift of about $3^{\circ} \mathrm{C}$. Moreover, DSC works with a constant cooling rate whereas the PVT measurements were done with natural cooling.

In any case, in the PVT the crystallization of PET should be noticed at temperatures higher than $185^{\circ} \mathrm{C}$, confirming that at the temperatures at which the shear rates are applied, the PET should be already crystallized. For an applied pressure of $1200 \mathrm{bar}$, the shear rates are applied at higher temperatures $\left(201^{\circ} \mathrm{C}\right.$ and $\left.171^{\circ} \mathrm{C}\right)$, but it should be considered that with pressure the $T_{c}$ of PET is also shifted to higher temperatures, so PET must be, also in this case, crystallized.

a)

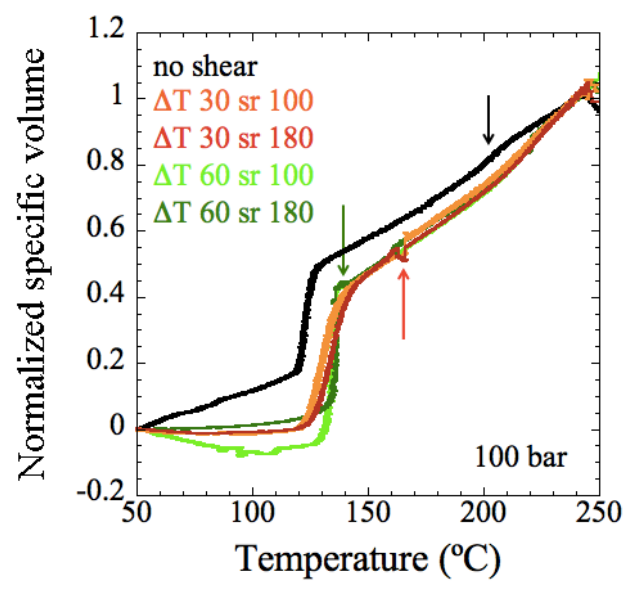

c)

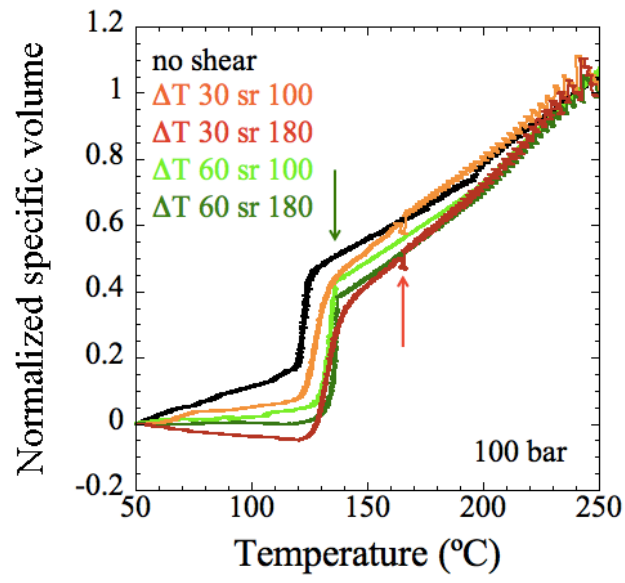

b)

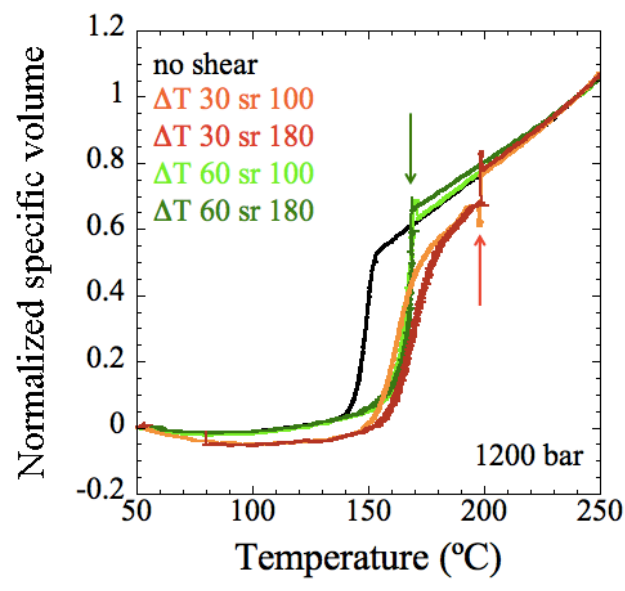

d)

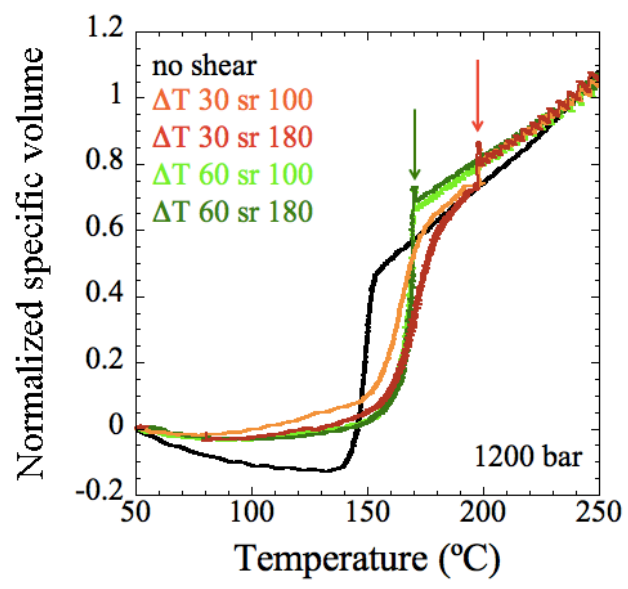


e)

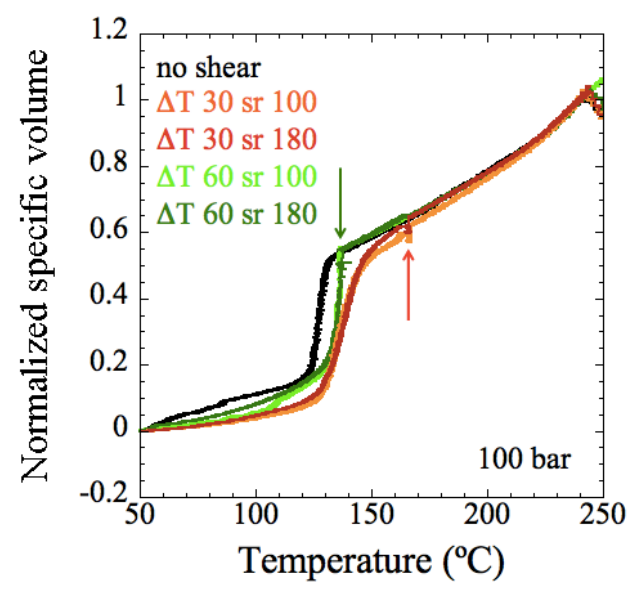

f)

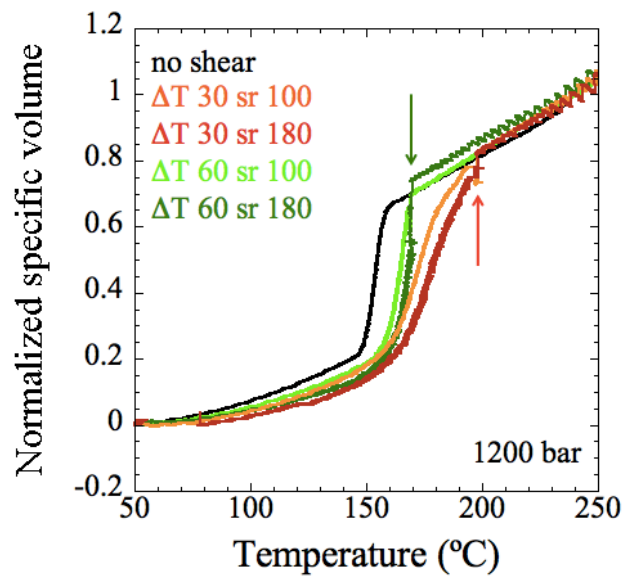

Figure 10. The normalized specific volume measured during cooling from the melt for PP/PET (a and b), PP/PET/TiO 2 (c and d) and PP/PET/CNT (e and f) at the indicated conditions. The black arrow marks the crystallization of PET in Figure 10a. The arrow in green and red in all figures marks the dip due to the shear pulse.

The results for the $\theta$ parameter are shown in Figure 11 for the PBNANO's. When shear is applied at low undercooling for $\mathrm{PP} / \mathrm{PET} / \mathrm{TiO}_{2}$, it can be observed that $\mathrm{TiO}_{2}$ increases $T_{c}$ only at intermediate and high pressures. The same trend is observed for PP/PET/CNT, although the increase is more severe. This enhancement with respect to the binary blend PP/PET results from the presence of some nanoparticles in the PP matrix.

At high undercooling, the presence of $\mathrm{TiO}_{2}$ does not change the crystallization temperature, $T_{c}$, but rather it is reduced with $\mathrm{TiO}_{2}$ at high pressures. In the case of $\mathrm{PP} / \mathrm{PET} / \mathrm{CNT}$, the $T_{c}$ is lower than for the binary blend. In both PBNANO's (i.e., $\mathrm{PP} / \mathrm{PET} / \mathrm{TiO}_{2}$ and $\mathrm{PP} / \mathrm{PET} / \mathrm{CNT}$ ) this behavior can be explained considering that the PP crystallization for the systems containing nanoparticles occurs as soon as shear is applied.

It is interesting to note that the increase of $\theta$ parameter is more significant, at low undercooling for PBNANO's than for the corresponding nanocomposites. When shear is applied the crystallization temperature depends on two factors (if the applied shear is the same); the nucleating efficiency and the available surface. According to DSC, the nucleating efficiency is higher for $\mathrm{PP} / \mathrm{PET} / \mathrm{TiO}_{2}(37 \%)$ than for $\mathrm{PP} / \mathrm{TiO}_{2}(0$ 
\%) since $\mathrm{TiO}_{2}$ does not act as a nucleating agent. Regarding the samples with CNT, PP/CNT (67\%) has a nucleating efficiency higher than that of the PP/PET/CNT (48 $\%)$. If the available surface is considered for PBNANOs in addition to the surface of PET droplets, there are also some nanoparticles dispersed in the PP matrix. For the samples with CNTs, according to PVT results, the available surface overcomes the effect of the nucleating efficiency, obtaining higher $\theta$ values for PP/PET/CNT.
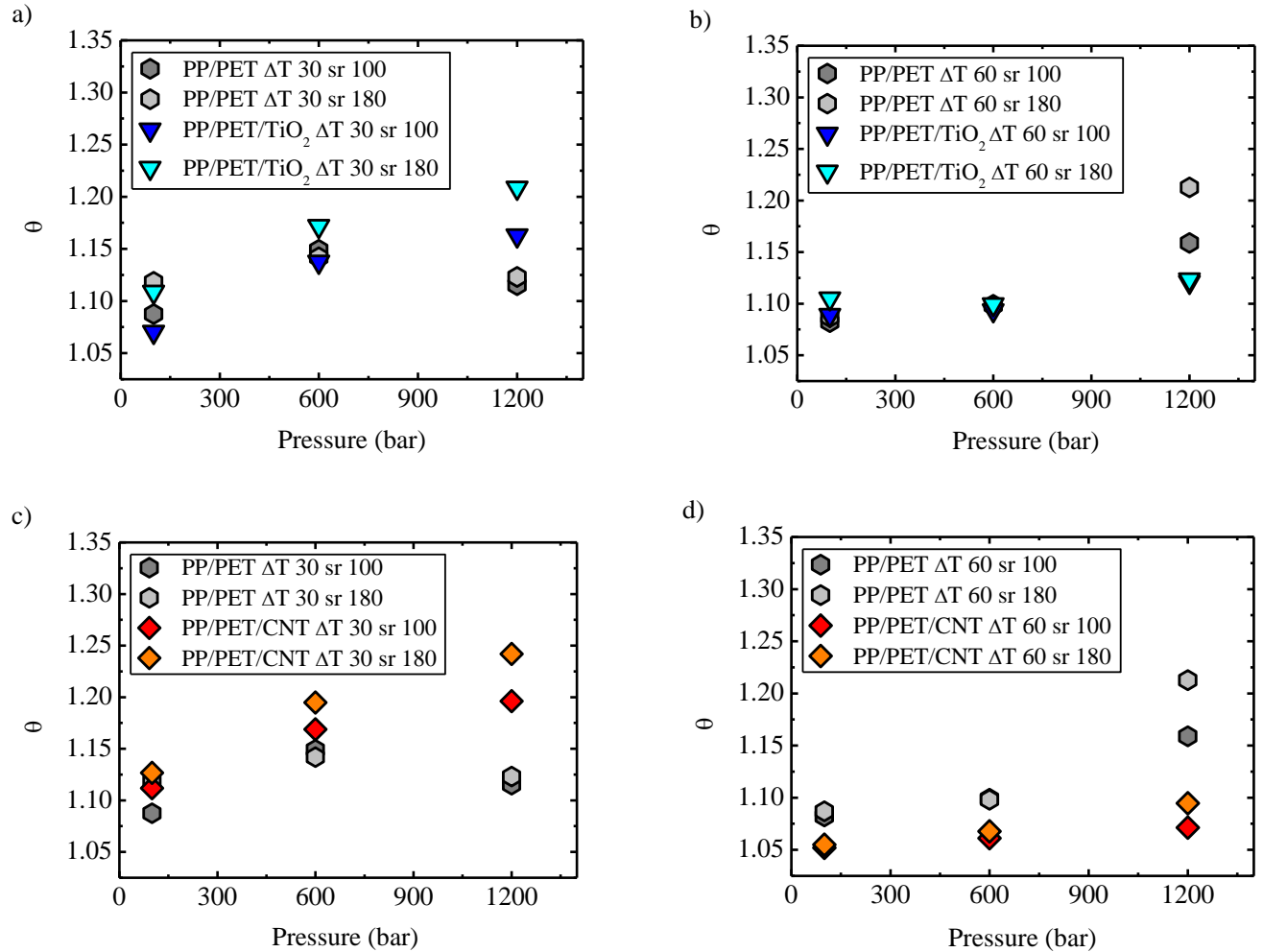

Figure 11. Theta parameter, defined in the text, as a function of pressure for PP/PET, PP/PET/TiO 2 (a and b) and PP/PET/CNT (c and d).

\section{Orientation and crystal phases}

The orientation of the crystals of PP/PET blends and PBNANOs is shown in Figure 12. In the absence of shear, the crystals are, as expected, unoriented. When shear is applied at low undercooling, it can be observed that there is some orientation of the crystals, more significant for PP/PET/CNT than for PP/PET/TiO 2 and PP/PET. The orientation of the gamma crystals is the most significant in comparison with the alpha crystals, as it has been observed for pure PP and its nanocomposites. PP/PET/CNT shows the highest orientation because after applying the shear pulse, the relaxation of the chains is hindered more significantly than in the other systems, thereby retaining the orientation. When shear is applied at high undercooling, PP/PET remains 
unoriented, whereas $\mathrm{PP} / \mathrm{PET} / \mathrm{TiO}_{2}$ shows the highest orientation. This is probably because for PP/PET/CNT, as soon as the shear pulse starts, PP starts to crystallize, so it does not reach the maximum orientation.

a)

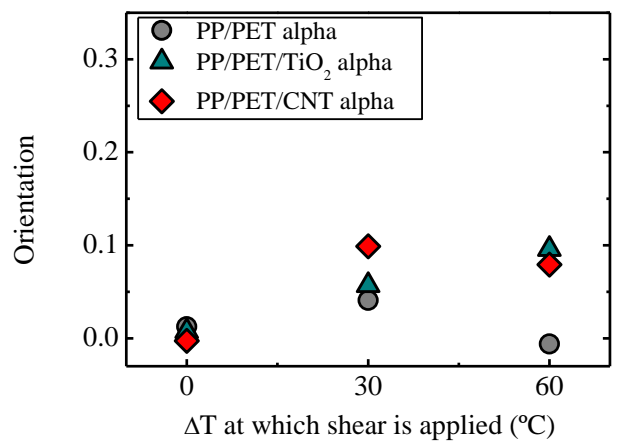

b)

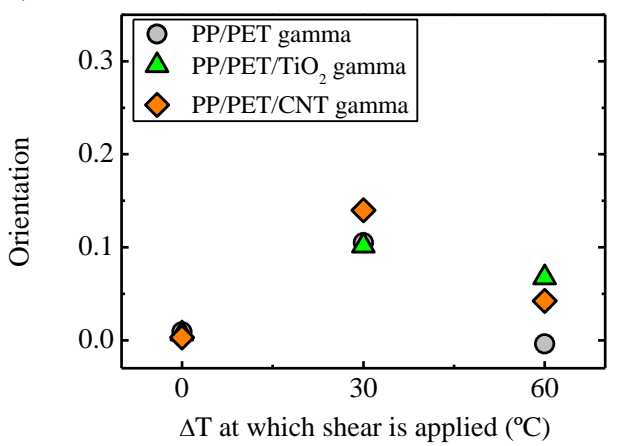

Figure 12. The orientation of the a) alpha and b) gamma crystals for PP/PET blend and its PBNANOs for the samples submitted to 1200 bar applying shear (at two different undercoolings, $\Delta \mathrm{T}=30$ and $\left.60^{\circ} \mathrm{C}\right)$ or without shear $\left(\Delta \mathrm{T}=0^{\circ} \mathrm{C}\right.$ in the $\mathrm{x}$-axis $)$.

The total crystallinity of $\mathrm{PP} / \mathrm{PET}$ and PBNANOs $\left(\mathrm{PP} / \mathrm{PET} / \mathrm{TiO}_{2}\right.$ and $\mathrm{PP} / \mathrm{PET} / \mathrm{CNT}$ ) and the amount of the different crystalline phases are shown in Figure 13. The total crystallinity is similar to that of PP and its nanocomposites, and in this case, there is also a slight increase of crystallinity when shear is applied. The samples obtained for a pressure of 1200 bar have been analyzed, thus under conditions at which only alpha and gamma crystal phases are formed. For the quiescent state, a similar amount of alpha and gamma phases are formed in the case of PP/PET and PP/PET/TiO 2 systems. However, for PP/PET/CNT PBNANO more alpha phase than gamma phase is formed, because, as a percolated network is created (Figure 5), the system has longer relaxation times, which retains the orientation of the chains promoting the formation of oriented crystalline structures. Nevertheless, at high undercooling, similar content of alpha and gamma phases are formed, because crystallization happens as soon as the shear rate is applied. Finally, for the binary blend as well as for PP/PET/TiO 2 , a higher amount of alpha phase than gamma phase is formed, due to the orientation of the chains, which in this case induces oriented crystalline structures favoring the formation of alpha phase over gamma (again, see [17]).

In the Supporting information, heating DSC scans are shown and the different crystal phase contents obtained from DSC are compared with X-ray results. 

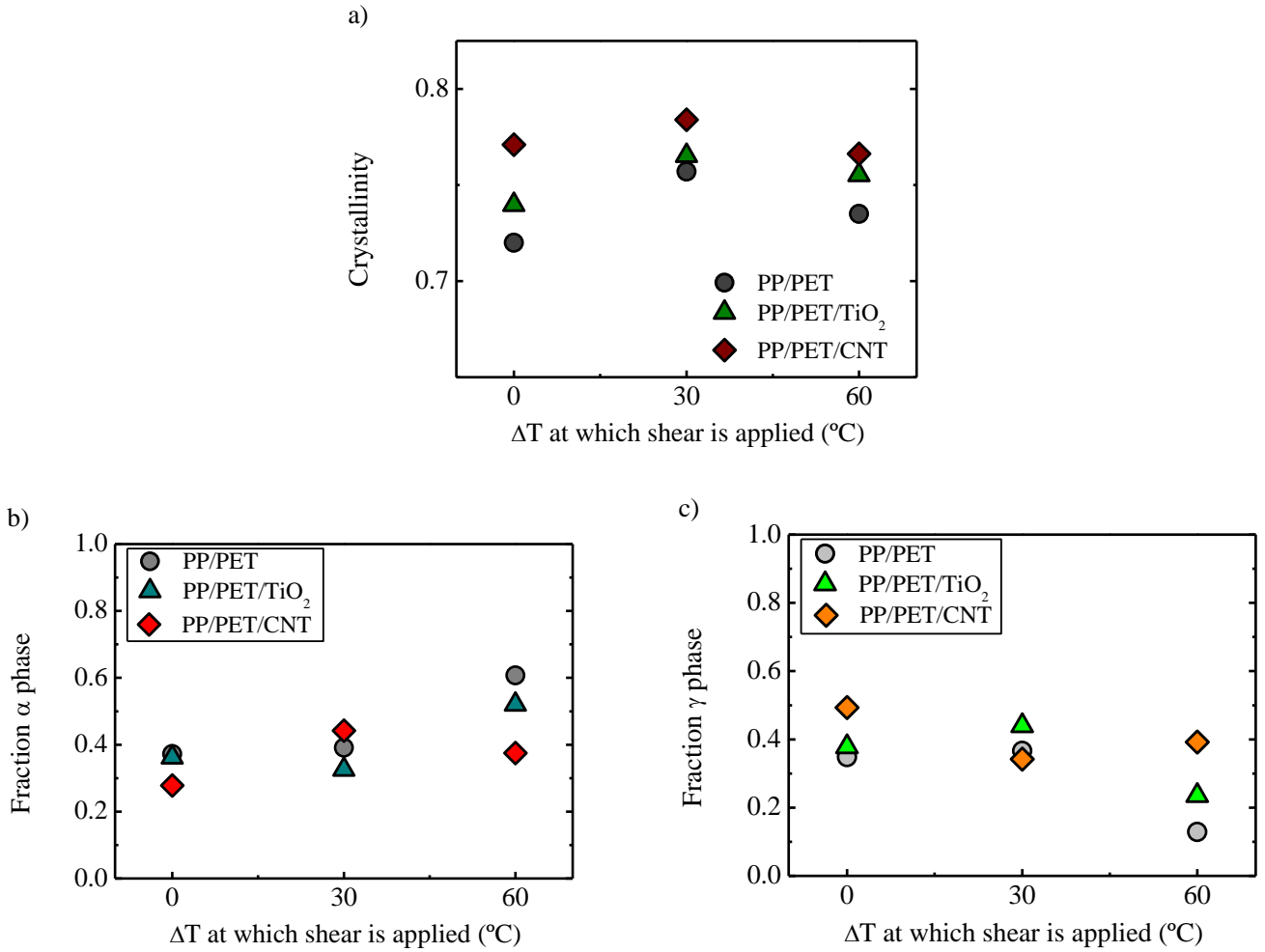

Figure 13. a) Total crystallinity and b) alpha and c) gamma fraction for PP/PET binary blend and PP/PET/TiO 2 and PP/PET/CNT PBNANOs summited to 1200 bar applying shear (at two different undercoolings $\Delta \mathrm{T}=30$ and $60{ }^{\circ} \mathrm{C}$ ) or without shear $\left(\Delta \mathrm{T}=0{ }^{\circ} \mathrm{C}\right.$ in the $\mathrm{x}$ axis $)$.

\section{CONCLUSIONS}

The adequacy of combining PVT, rheology, and X-ray measurements to investigate the effect of pressure and shear flow on the crystallization of polypropylene, polypropylene nanocomposites, as well as nanocomposites based on PP/PET blends, has been demonstrated.

Nanoparticles which have different nucleating efficiency have been employed: $\mathrm{TiO}_{2}$ that does not act as a nucleating agent and CNTs that have higher nucleating efficiency $(67 \%)$ than PET $(27 \%)$ on the PP matrix. The results show that $\mathrm{TiO}_{2}$ nanoparticles increase the crystallization temperature under shear, due to the local flow generated between particles. In the case of CNTs, there is a combined influence of the nucleating effect and flow that leads to a more pronounced increase in the crystallization temperature.

Comparing both types of nanoparticles, $\mathrm{TiO}_{2}$, and $\mathrm{CNTs}$, morphological and rheological experiments show that there is a stronger interaction of the latter with the 
polymer chains, giving rise to a percolated network. This is relevant because it is demonstrated that the orientation is more significant in systems which contain CNT nanoparticles. Due to the percolated network, the relaxation time is increased, so the orientation of the chains is retained, thereby promoting the formation of oriented crystalline structures. This is also reflected in a more abundant alpha phase than gamma phase in nanocomposites with CNTs, notwithstanding, at high undercooling similar content of alpha and gamma phases are formed, because crystallization happens as soon as shear rate is applied.

Regarding the effect of pressure, the results show that the presence of nanoparticles or PET does not significantly influence the dependence of crystallization temperature with pressure.

In the case of PBNANO's, the presence of nanoparticles increases the crystallization temperature under shear in comparison with the binary blend at low undercooling. This is due to the presence of nanoparticles in the PP matrix. The increase is more severe in the presence of CNTs. The orientation of the crystals is more severe for the PBNANO containing CNTs and this is related to the interactions between CNTs and PP chains. Similarly to the results obtained for PP/CNT, for PP/PET/CNT PBNANO a percolated network is formed that results in longer relaxation times, which prevents the disorientation of the crystals.

Comparing the nanocomposites and PBNANO's it has been found that the effect of shear is slightly higher for PBNANO's than the nanocomposites. This can be explained by considering that some of the nanoparticles are located in the PP matrix. Therefore, the presence of these nanoparticles along with the PET droplets results in a higher amount of available surface that increases more significantly the crystallization temperature. On the contrary, the effect of pressure is not altered by the presence nanoparticles or PET phase, the results being quite similar for nanocomposites and PBNANO's.

\section{ACKNOWLEDGEMENTS}

Financial support from “Teknologia eta Berrikuntza Sarea 2017” (GFA/DFG) and Basque Government (GIC IT-309-19) is acknowledged. Projects POCTEFA REVALPET EFA064/15 (EU Interreg) and MINECO MAT2017-83014-C2-1-P are 
also gratefully acknowledged. L. S. thanks Spanish Ministry (FPU) for her PhD grant and the grant to do the internship in Eindhoven University of Technology for 3 months.

\section{REFERENCES}

[1] Moniruzzaman, M.; Winey, K. I. Polymer Nanocomposites Containing Carbon Nanotubes. Macromolecules 2006, 39, 5194-5205.

[2] Winey, K. I.; Vaia, R. A. Polymer Nanocomposites. MRS Bulletin 2007, 32, 314-322.

[3] Paul, D. R.; Robeson, L. M. Polymer nanotechnology: Nanocomposites. Polymer 2008, 49, 3187-3204.

[4] Kim, H.; Abdala, A. A.; Macosko, C. W. Graphene/Polymer Nanocomposites. Macromolecules 2010, 43, 6515-6530.

[5] Elias, L.; Fenouillot, F.; Majeste, J. C.; Cassagnau, P. Morphology and rheology of immiscible polymer blends filled with silica nanoparticles. Polymer 2007, $48,6029-6040$.

[6] Elias, L.; Fenouillot, F.; Majesté, J. C.; Alcouffe, P.; Cassagnau, P. Immiscible polymer blends stabilized with nano-silica particles: Rheology and effective interfacial tension. Polymer 2008, 49, 4378-4385.

[7] Fenouillot, F.; Cassagnau, P.; Majesté, J. C. Uneven distribution of nanoparticles in immiscible fluids: Morphology development in polymer blends. Polymer 2009, 50, 1333-1350.

[8] Scaffaro, R.; Botta, L. Nanofilled Thermoplastic-Thermoplastic Polymer Blends. in: Nanostructured Polymer Blends; Thomas, S.; Shanks, R.; Chandrasekharakurup, S. (Eds.), Elsevier: United Kingdom, 2014; Chapter 5, pp 133160.

[9] Taguet, A.; Cassagnau, P.; Lopez-Cuesta, J. M. Structuration, selective dispersion and compatibilizing effect of (nano)fillers in polymer blends. Progress in Polymer Science 2014, 39, 1526-1563.

[10] Van der Beek, M. H. E.; Peters, G. W. M.; Meijer, H. E. H. The Influence of Cooling Rate on the specific Volume of Isotactic Poly(propylene) at Elevated Pressures. Macromol. Mater. Eng. 2005, 290, 443-455. 
[11] Van der Beek, M. H. E.; Peters, G. W. M.; Meijer, H. E. H. Influence of Shear Flow on the Specific Volume and the Crystalline Morphology of Isotactic Polypropylene. Macromolecules 2006, 39, 1805-1814.

[12] Forstner, R.; Peters, G. W. M.; Meijer, H. E. H. A Novel dilatometer for PVT Measurements of polymers at High cooling and shear rates. Intern. Polymer Processing XXIV 2009, 2, 114-121.

[13] Van Drongelen, M.; Van Erp, T. B.; Peters G. W. M. Quantification of non-isothermal, multi-phase crystallization of isotactic polypropylene: The influence of cooling rate and pressure. Polymer 2012, 53, 4758-4769.

[14] Van Erp, T. B.; Balzano, L.; Spoelstra, A. B.; Govaert, L. E.; Peters, G. W. M. Quantification of non-isothermal, multi-phase crystallization of isotactic polypropylene: The influence of shear and pressure. Polymer 2012, 53, 5896-5908.

[15] Van Meerveld, J.; Peters, G. W. M.; Hütter, M. Towards a rheological classification of flow induced crystallization experiments of polymer melts. Rheol Acta 2004, 44, 119-134.

[16] Van Drongelen, M.; Gahleitner, M.; Spoelstra, A. B.; Govaert, L. E.; Peters, G. W. M. Flow-induced solidification of high-impact polypropylene copolymer compositions: Morphological and mechanical effects. Journal of Applied Polymer Science 2015, 42040 .

[17] Roozemond, P. C.; Van Erp, T. B.; Peters, G. W. M. Flow-induced crystallization of isotactic polypropylene: Modeling formation of multiple crystal phases and morphologies. Polymer 2016, 89, 69-80.

[18] Peters, G.W.M.; Balzano, L.; Steenbakkers, R. J. A. Flow-induced crystallization. In Handbook of Polymer Crystallization, Eds. Piorkowska, E. and Rutledge, G. C. John Wiley \& Sons 2013.

[19] Somani, R. H.; Hsiao, B. S.; Nogales, A.; Srinivas, S.; Tsou, A. H.; Sics, I.; Balta-Calleja, F. J.; T. A. Ezquerra. Structure development during shear flowinduced crystallization of i-PP: In-situ Small Angle X-ray Scattering study. Macromolecules 2000, 33, 9385-9394.

[20] Wang, Z.; Ma, Z.; Li, L. FLow-induced crystallization of polymers: molecular and thermodynamic considerations. Macromolecules 2016, 49, 1505-1517.

[21] Caelers, H. J. M.; Parodi, E.; Cavallo, D.; Peters, G. W. M.; Govaert, L. E. Deformation and failure kinetics of iPP polymorphs. Journal of Polymer Science Part B: Polymer Physics 2017, 55, 729-747. 
[22] Thomas, S.; Arif, M. P.; Gowd, E: B.; Kalarikkal, N. Crystallization in multiphase polymer systems. Elsevier 2017.

[23] Lin, J. M.; Yang, S. H.; Hu, B. C.; Song, Y. N.; Ren, J. Y.; Lei, J.; Ji, X.; Li, Z. M. Quantification of pressure-induced $\gamma$-crystals in isotactic polypropylene: The influence of shear and carbon nanotubes. Polymer Crystallization 2018, 1, 10002.

[24] Forstner, R.; Peters, G.W.M.; Meijer, H.E.H. A novel dilatometer for PVT measurements of polymers at high cooling and shear rates. International Polymer Processing 2009, 24, 114-121.

[25] Housmans, J. W.; Balzano, L.; Adinolfi, K.; Peters, G.W.M.; Meijer, H.E.H. Dilatometry: a tool to measure the influence of cooling rate and pressure on the phase behavior of nucleated polypropylene, Macromolecular Material \& Engineering 2009, 294, 231-243.

[26] van der Burgt, F.P.T.J.,; Rastogi, S.; Chadwick, J.C.; Rieger, B.; Journal of Macromolecular Science - Physics, 2003, 41, 1091-1104

[27] Murthy, N.S.; Minor, H. General procedure for evaluating Polymer, 1990, 31, 996-1002

[28] Fillon, B.; Wittmann, J. C.; Lotz, B.; Thierry, A. Self-nucleation and recrystallization of isotatic polypropylene ( $\alpha$ phase) investigated by differential scanning calorimetry. J. Polym. Sci., Part B: Polym. Phys. 1993, 31, 1383-1393.

[29] Michell, R. M.; Mugica, A.; Zubitur, M.; Müller, A. J. Self- Nucleation of crystalline phases within homopolymers, polymer blends, copolymers, and nanocomposites. Adv. Polym. Sci. 2015, 276, 215-256.

[30] Li, W.; Karger-kocsis, J.; Schlarb, A. K. Dispersion of TiO2 Particles in PET/PP/TiO2 and PET/PP/PP-g-MA/TiO2 Composites Prepared with different Blending Procedures. Macromolecular Material and Engineering 2009,294, 582589.

[31] Sangroniz, L.; Ruiz, J. L.; Sangroniz, A.; Fernández, M.; Müller, A. J.; Santamaria, A. Polyethylene terephthalate/low density polyethylene/titanium dioxide blend nanocomposites: Morphology, crystallinity, rheology, and transport properties. Journal of Applied Polymer Science 2019, 136, 46986.

[32] Cardinaud, R.; McNally, T. Localization of MWCNTs in PET/LDPE blends. European Polymer Journal, 2013, 49, 1287-1297. 
[33] Pötschke, P.; Abdel-Goad, M.; Alig, I.; Dudkin, S.; Lellinger, D. Rheological and dielectrical characterization of melt mixed polycarbonate-multiwalled carbon nanotube composites, Polymer 2004, 45, 8863-8870.

[34] Palierne, J. F. Linear rheology of viscoelastic emulsions with interfacial tension, Rheol. Acta 1990, 29, 204-214.

[35] Gramespacher, H.; Meissner, J. Interfacial tension between polymer melts measured by shear oscillations of their blends, J. Rheol. 1992, 36, 1127-1141.

[36] Housmans, J. W.; Steenbakkers, R. J. A.; Roozemond, P. C.; Peters, G. W. M.; Meijer, H. E. H. Macromolecules 2009, 42, 5728-5740.

[37] Eder, G.; Janeschitz-Kriegl, H. In structure development during processing: crystallization [Chapter 5]. In: Meijer, H. E. H., editor. Processing of polymers. Materials science and technology: a comprehensive treatment, vol. 18. Wiley-VCH and Weinheim; 1997. p. 269-342.

[38] Zuidema, H.; Peters, G. W. M.; Meijer, H. E. H. Development and validation ofa recoverable strain based model forflow-induced crystallization of polymers. Macromol Theory Simul 2001, 10, 447-460.

[39] Szkudlarek, E.; Piorkowska, E.; Boyer, S.A.E.; Haudin, J. M.; Gadzinowska, K. Nonisothermal shear-induced crystallization of polypropylene-based composite materials with montmorillonite. European Polyemr Journal 49, 2013, 21092119.

[40] Nowackia, R.; Monasseb, B.; Piorkowskaa, E.; Galeskia, A.; Haudin, J. M. Spherulite nucleation in isotactic polypropylene based nanocomposites with montmorillonite under shear, Polymer 45, 2004, 4877-4892.

[41] Wang, K.; Liang, S.; Deng, J.; Yang, H.; Zhang, Q.; Fu, Q. The role of clay network on macromolecular chain mobility and relaxation in isotactic polypropylene/organoclay nanocomposites. Polymer 2006, 47, 7131-44.

[42] Jay, F.; Haudin, J.M.; Monasse, B. Shear-induced crystallization of polypropylenes: effect of molecular weight. J Mater Sci 1999, 34, 2089.

[43] Copppola, S.; Grizzuti, N.; Maffetone, P. L. Microrheological Modeling of Flow-Induced Crystallization. Macromolecules, 2001, 34, 5030-5036.

[44] Hwang, W. R.; Peters, G. W. M.; Hulsen, M. A.; Meijer, H. E. H. Modeling of flow induced crystallization of particle-filled polymers. Macromolecules

2006, 39, 8389-98. 
[45] D’Haese, M.; Puyvelde, P. V.; Langouche, F. Effect of Particles on the Flow-Induced Crystallization of Polypropylene at Processing Speeds Macromolecules 2010, 43, 2933-2941.

[46] Yang, S.G.; Zhang, Z.; Zhou, D.; Wang, Y.; Lei, J.; Li, L.; Li, Z.M. Flow and Pressure Jointly Induced Ultrahigh Melting Temperature Spherulites with Oriented Thick Lamellae in Isotactic Polypropylene. Macromolecules 2015, 48, 5834-5844.

[47]https://perkinelmer.cl/wp-content/uploads/2018/05/Crystallization $\underline{\text { Temperature-vs.-Cooling-Rate-the-Link-with-Real-Life-Polymer-Processes.pdf }}$ 